Hedonic model of segmentation with horizontal differentiated housing

MASHA MASLIANSKAIA-PAUTREL 


\title{
Hedonic model of segmentation with horizontal differentiated housing.
}

\author{
Preliminary version \\ Masha Maslianskaia-Pautrel ${ }^{*}$
}

January 12, 2012

Abstract

The purpose of this paper is to study how the hedonic equilibrium is modified when group-wise consumer heterogeneity with horizontal differentiated housing supply is assumed. We complete the hedonic segmentation analysis of Baudrv and Maslianskaïa-Pautrel (2011a b) for vertical differentiation of housing supply by investigating the more realistic case of horizontal differentiation. Our results confirm the segmentation of the hedonic price function at equilibrium and the discontinuity of the implicit price of environmental quality on the borders of the segments. We also demonstrate that horizontal differentiation can lead to a partial sorting of consumer demand for housing attributes at hedonic equilibrium. Finally we show that according to model specification, the group-wise heterogeneity with horizontal differentiation can lead to modification of welfare assessment related to changes in environmental quality.

Keywords : Hedonic model, Group-wise consumers' heterogeneity, Horizontal differentiation

\section{Introduction}

The hedonic estimation is now a usual tool in environmental economic valuation of local amenities or nuisances (see for example, Bovle and Kiel, 2001; Simons and Saginor, 2006). It is based on the Rosen (1974) theoretical

\footnotetext{
${ }^{*}$ GAINS-TEPP (University of Le Mans) and LEMNA (University of Nantes); maria.pautrel@univ-lemans.fr

${ }^{\dagger}$ We are particularly indebted to Marc Baudry and Yann Rebillé for their valuable guidance. We also wish to acknowledge Xavier Pautrel for his comments on this paper. We remain responsible for any errors.
} 
model which analyzes the properties of the hedonic price function that arises when a continuum of heterogeneous consumers choose among a continuum of differentiated products. Consumers are supposed to be distributed continuously between the extreme values of their heterogeneity parameters. Nevertheless, empirical observations suggest that several population groups (such that active population and retirements, residents working in this area and residents working outside the the area...) may coexist on a same territory. This is often the case for heterogeneous territories with rich natural capital on the one hand and high industrial development on the other hand. If such heterogeneous groups of consumers coexist on the same area, what are the implications for hedonic valuation of the environmental goods?

Baudry and Maslianskaïa-Pautrel (2011a, b) answer that question, investigating a groupe-wise buyers' heterogeneity in the housing market with vertical differentiation of the supply. The vertical differentiation means that all consumers share the same preferences about housing attributes and differ by their income or preferences between housing and other consumption. The authors demonstrate that such discrete heterogeneity with vertical differentiation can lead to a hedonic price function segmentation.

The purpose of this paper is to reexamine these results in the case of an horizontal differentiation of the housing supply. It is motivated by the fact that with different groups on the same territory (such the active population and retirements for example), we expect that the preferences on housing attributes are different between groups. It means that the aggregation of housing attributes into housing service index depends on the parameters group. Thus the housing supply is horizontally differentiated, like in Lancaster (1966).

We develop a theoretical hedonic model of segmentation based on the same structure than Baudrv and Maslianskaïa-Pautrel (2011a,b). Nevertheless our modeling differs significantly in assumption about consumers behavior because the differentiation is horizontal.

The two main features of our modeling, group-wise heterogeneity and horizontal differentiated housing supply, play a major role in shaping the outcome of the housing market. First, the distinction between continuous and group-wise consumers' heterogeneity is important in the hedonic model. In the first case, when the heterogeneous parameter is distributed continuously between two limits, each agent is atomistic and her housing purchase cannot impact market prices: consumers are "hedonic price taker". ${ }^{1}$. In the second case, when the heterogeneous parameter distribution is discrete, consumers of the same group are not still atomistic, their mass is not null but

\footnotetext{
${ }^{1}$ Continuous buyers heterogeneity is assumed in Rosen (1974), as well as in sorting models dealing with hedonic price function analysis (Epple and Platt, 1998; Kuminoff, 2009, among others).
} 
is equal to the group's weight. Sellers have to take into account the choice of each group when they propose their housing prices. Consequently the market equilibrium results from strategic interactions between sellers and buyers groups. This group-wise heterogeneity founds the hedonic model of segmentation firstly developed by Baudrv and Maslianskaïa-Pautrel (2011a)

Second, horizontal differentiation generally means that different groups of consumers have different preferences for the same house (with the same attributes). ${ }^{2}$ However it is possible that, in a particular case, all groups have the same valuation of housing (when one or other housing attributes is absent or at its minimal level). In the present paper, we study two cases: when all consumers value in the same way the housing without environmental quality, and when different groups have specific valuation of housing without environmental or intrinsic quality. From the methodological point of view, this distinction is about different specifications of Spence-Mirrlees single-crossing condition for consumer preferences. From the economic point of view, this distinction implies different consequences for the hedonic equilibrium, the hedonic price function, the implicit prices of housing attributes and thus for the environmental hedonic valuation.

Our modeling of group-wise consumers heterogeneity with horizontal housing supply differentiation completes existing hedonic approaches: the "traditional hedonic" model developed by Rosen (1974) and the "new hedonic" or "sorting" models developed since the seminal article by Tiebout (1956) (see for exemple, Epple and Platt, 1998; Epple and Sieg, 1999, Kuminoff, 2009). ${ }^{3}$

Our main results are threefold. First, we generalize the Baudry and Maslianskaïa-Pautrel (2011a) result for the case of horizontal differentiation: the group-wise consumers heterogeneity leads to a segmentation of the hedonic price function in the housing market equilibrium. Hedonic price function is continuous, but builed of different segments corresponding to each consumer group. Consequently, on the one hand, the hedonic price function we obtain, is based on individual characteristics, while in the "usual" hedonic estimation procedure, individual characteristics appear only on the second stage, once the hedonic price function estimated. On the other hand, the segmentation of the hedonic price function implies a discontinuity of the

\footnotetext{
${ }^{2}$ Horizontal differentiation of the housing supply is commonly assumed in the hedonic literature (see the Rosen (1974)'s model for example). Kuminoff (2006) and Baver et al. (2005) also introduce the horizontal differentiation in their sorting models, by assuming that the differentiation is about households' preferences for different local public goods provided by each community. Those public goods can be viewed as different environmental characteristics of housing, such that air quality (air quality in a given community can be constant if the community area is relatively small).

${ }^{3}$ Figure 8 in the Appendix $\mathrm{A}$ presents the main assumption and the main results of those three approaches.
} 
implicit price of environmental quality of housing on the borders of the segments. That invalidates the second stage of the procedure where the implicit price function is assumed to be continuous.

Our second result is about sorting of the consumers demand. We demonstrate that with a horizontal differentiation of housing supply, the segmentation of hedonic price function can lead to partial sorting of the demand for housing attributes by consumers groups (namely, in the case of group specific valuation of alternatives "outside the environmental quality" and "outside the intrinsic quality"). This result differs from the case of vertical differentiated housing supply studied in Baudrv and Maslianskaïa-Pautrel $(2011 \mathrm{a}, \mathrm{b})$, and can be viewed as dual to the partial two-dementional stratification by consumer income and preferences in sorting models (Epple and Platt, 1998).

Finally, the third result is about consumers surplus extraction in equilibrium. Fixed supply and short-run assumption lead the sellers of a part of housing to extract at equilibrium, the all consumer surplus of one or more groups. We show that according to the model specifications, the group with the lowest parameter of preferences for housing attributes it is not necessarily the one with whole surplus extracted. Thus the segmentation have implications for the assessment of welfare related to changes in environmental quality.

Section 1 presents the basic model and general equilibrium condition. Section 2 derives equilibrium condition and analyses its property. Section 3 presents two applications for a nested CES direct utility function.

\section{General framework}

The economy has two consumption goods: housing and a numeraire. Housing is is characterized by an index of housing service $H$, function of two housing attributes: $H=h(Q, S)$, where $S$ is intrinsic attribute and $Q$ is environmental attribute of the house. As in the Rosen (1974) model, the housing price depends on the housing service index $P=P(Q, S) .{ }^{4}$

\subsection{Consumer behavior}

Following the model of Rosen (1974), we consider an individual who has distribute its income $R$ between the purchase of a $X$ (chosen as the numeraire) and a housing, characterized by a level of service $H=h(Q, S)$. A

\footnotetext{
${ }^{4}$ In this respect our model differs from sorting models, where the function of housing service is supposed to be separated between a "quantitative" index of intrinsic characteristics of dwelling $S$ and an "qualitative" index of its environmental and neighborhood characteristics $Q$, and only the qualitative index determines the price of housing (cf. Kuminoff, 2009). In our case, the price depends on both intrinsic and environmental characteristics of dwelling.
} 
household's utility depends on the housing service level and on its consumption of a composite numeraire private good. Households are heterogeneous by groups in their tastes about housing attributes, $\beta .^{5}$ Then the housing service index is written as:

$$
H=h\left(Q, S \mid \beta_{i}\right) .
$$

We assume the function $h(\cdot)$ belongs to the class $\mathcal{C}^{1}$, is increasing and concave, and satisfies the Spence-Mirrlees single crossing condition in $\beta:^{6}$

$$
\frac{\partial}{\partial \beta}\left[\frac{\partial H / \partial Q}{\partial H / \partial S}\right]>0, \forall \beta
$$

Group-wise heterogeneity means that there are $N$ different households groups such that the share of population in each group is equal to $\eta_{i}$ :

$$
\sum_{i=1}^{N} \eta_{i}=1 .
$$

Households preferences are homogenous inside of each group. We assume that groups are ordering by increasing order of the parameter $\beta$ :

$\beta_{1}<\beta_{2}<\ldots<\beta_{N}$. Then the household of the same group have the same utility function and the same budget constraint. In addition, the individual optimizing behavior corresponds to the optimizing behavior of the group which the individual belongs.

The group's $i$ direct utility function is given by

$$
U\left(h\left(Q, S \mid \beta_{i}\right), X \mid \Omega\right),
$$

where $\beta_{i}$ is the parameter of heterogeneous preferences for housing attributes, $\Omega$ is a set of parameters common to all consumers. To simplify the notations, we omit $\Omega$ thereafter. We assume that the utility function belongs to the class $\mathcal{C}^{2}$, is increasing and concave in its arguments.

The group's $i$ budget constraint is given by $X+P(Q, S)=R$.

Definition 1. Constrained utility function of an household from a group $i$ is

$$
V\left(h\left(Q, S \mid \beta_{i}\right), P\right) \equiv U\left(h\left(Q, S \mid \beta_{i}\right), R-P(Q, S)\right) .
$$

The utility constraint differs from the indirect utility in that it does not presuppose the optimizing behavior. It is obtained from the direct utility function of the individual by substituting quantity $X$ of the Hicksian composite good by the maximum quantity $R-P$, that the agent can afford given

\footnotetext{
${ }^{5}$ We assume that households are homogeneous in their income as well as their preferences between housing and other consumption.

${ }^{6}$ Without loss of generality we assume that $M R S_{Q S}$ is increasing in $\beta$.
} 
her budget constraints and the price $P$ associated with a given level $h(Q, S)$ of the index of housing services.

The constrained utility function is used, among others, in hedonic price models to introduce the fundamental concept of Rosen's bid function

Definition 2. Rosen's bid function for individual belonging to the group $i$ is defined implicitly by:

$$
V\left(h\left(Q, S \mid \beta_{i}\right), E_{i}^{(k)}\left(Q, S \mid \beta_{i}, u_{i}^{(k)}\right)\right)=u_{i}^{(k)},
$$

where $u_{i}^{(k)}$ stands for the level of utility attained by individual at her current location with the index of housing services $H=h\left(Q^{(k)}, S^{(k)}\right)$ and the price $P^{(k)}$.

The equation (4) defines the family of bid functions of individuals belonging to the group $i$ : $E_{i}^{(k)}=E_{i}^{(k)}\left(Q, S \mid \beta_{i}, u_{i}^{(k)}\right)$, parameterized by reference utility level $u_{i}^{(k)}$.

The utility maximization problem subject to individual budget constraint is equivalent to the problem of minimization of housing expenditure, that is the group's big funciton:

$$
\forall i, \quad \min _{u_{i}^{(k)} \in D U_{i}} E_{i}^{(k)}\left(h \mid R, u_{i}^{(k)}\right), \quad h \in \mathrm{Dh}_{i},
$$

where $\mathrm{Dh}_{i}$ is an interval (or union of intervals) of values $h$, characterizing housing purchased by consumers in the group $i$. Since the definition of bid function includes the consumer budget constraint (as defined from the utility function constraint), the optimization program of consumers has not constraint.

\subsubsection{Two cases of groups preferences}

We examine two different cases of groups preferences according to particular Spence-Mirrlees conditions for constrained utility function. The first one is the case with group identical valuation of "outside the environmental quality" housing, the second one is the case with group specific valuation of "outside the environmental quality" and "outside the intrinsic quality" housing. ${ }^{7}$

In the first case, we assume the constrained utility function satisfies the following Spence-Mirrlees conditions:

\footnotetext{
${ }^{7}$ The case with the group identical valuation of "outside the intrinsic quality" housing is similar from methodological point of view to the case with the group identical valuation of "outside the environmental quality" housing and does not study in this paper.
} 


$$
\begin{aligned}
& \forall S, \quad \frac{\partial}{\partial \beta}\left[\frac{\partial V / \partial h \cdot \partial h / \partial Q}{\partial V / \partial P}\right]<0, \forall \beta, \\
& \forall Q, \quad \frac{\partial}{\partial \beta}\left[\frac{\partial V / \partial h \cdot \partial h / \partial S}{\partial V / \partial P}\right]=0, \forall \beta
\end{aligned}
$$

Since in the space $(Q, S, P)$ the bid surface coincides with the surface of iso constrained utility, the groups' bid surfaces also satisfy the single-crossing properties $H^{\prime} 1$ and $\left(H^{\prime} 2\right.$ (see Figure 10.

Figure 1: Single-crossing property of groups' bid surfaces under $H^{\prime} 1$ and $H^{\prime} 2$

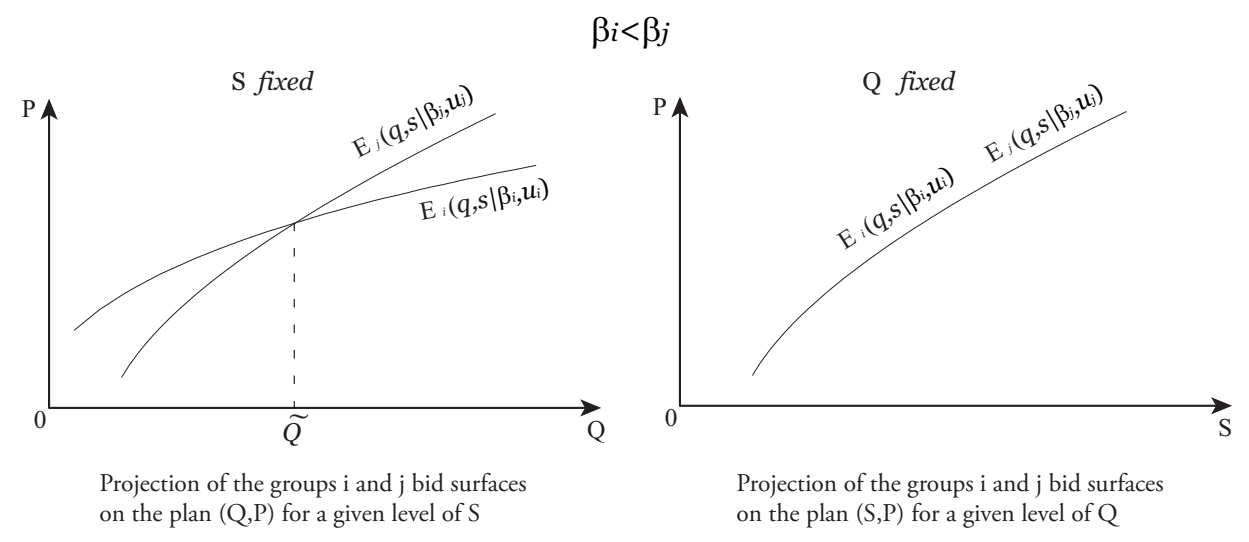

The condition $\left(H^{\prime} 11\right)$ means that in the space $(Q, P)$ for given value of $S$, the slopes of the bid curves are ordered in increasing order of the parameter $\beta$ : to right of the intersection of two bid curves, consumers in the group with a higher parameter $\beta$ willing to pay a higher price for housing with the same level of environmental quality $Q$ at a fixed level of the intrinsic quality $S$. Conversely, to the left of the intersection, consumers of this group willing to pay a lower price for housing with the same level of environmental quality at a fixed level of intrinsic quality. From the economic point of view it means that increasing of the level of parameter $\beta$ corresponds to households more cary about the environmental quality of housing.

The condition $\mathrm{H}^{\prime} 2$ means that all groups have the identical preferences about intrinsic housing attribute at each level of $Q$. In the space $(S, P)$, for given value of $Q$, bid curves of different groups coincide. In particularly, for $Q=0$ all groups value in the same way the housing services level: $E\left(0, S \mid \beta_{i}, u_{i}\right)=E\left(0, S \mid \beta_{j}, u_{j}\right) \forall i, j$ and $\forall S$. This explains the name of this case: group identical valuation of "outside the environmental quality" housing. ${ }^{8}$

\footnotetext{
${ }^{8}$ The case where all groups have the same preferences for environmental quality of
} 
In the second case, we assume the constrained utility function satisfies the following Spence-Mirrlees conditions:

$$
\begin{aligned}
& \forall S, \quad \frac{\partial}{\partial \beta}\left[\frac{\partial V / \partial h \cdot \partial h / \partial Q}{\partial V / \partial P}\right]<0, \forall \beta, \\
& \forall Q, \quad \frac{\partial}{\partial \beta}\left[\frac{\partial V / \partial h \cdot \partial h / \partial S}{\partial V / \partial P}\right]>0, \forall \beta
\end{aligned}
$$

Since in the space $(Q, S, P)$ the bid surface coincides with the surface of iso constrained utility, the groups' bid surfaces also satisfy the single-crossing properties ( $H^{\prime \prime} 1$ and $H^{\prime \prime} 2$ (see Figure 2 ).

Figure 2: Single-crossing property of groups' bid surfaces under $H^{\prime \prime} 1$ and $H^{\prime \prime} 2$

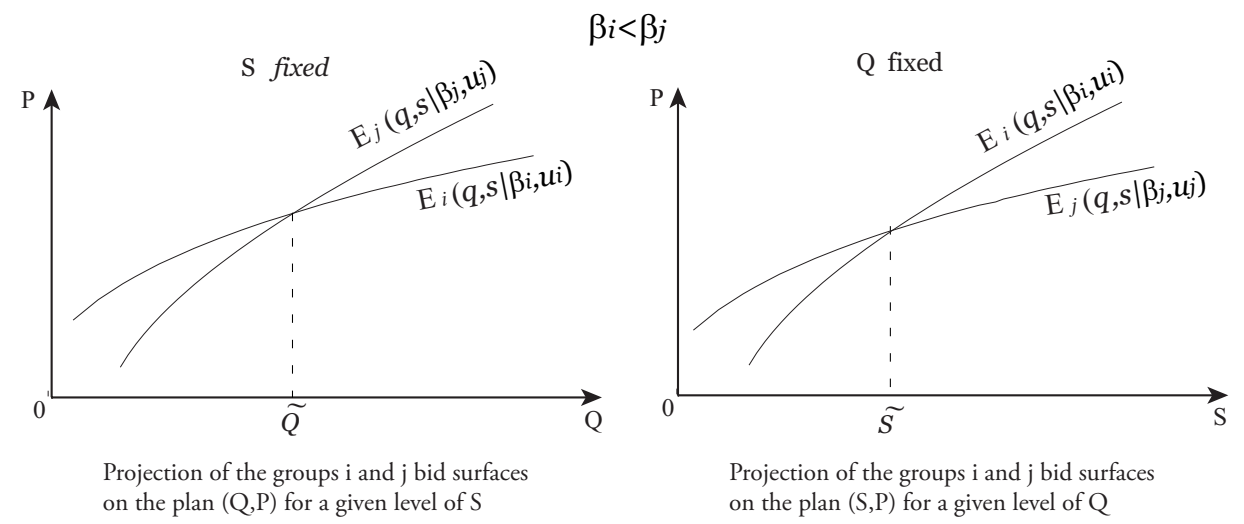

As in the previously described case, the condition (HI $H^{\prime \prime}$ means that in the space $(Q, P)$ for a fixed $S$, the slopes of the bid curves are ordered in increasing order of the parameter $\beta$ : on the right of the intersection of two bid curves, consumers of the group with a higher parameter $\beta$ willing to pay a stronger housing prices for the same level of environmental quality $Q$ given a fixed level of the intrinsic quality $S$. Conversely, on the left of the intersection, consumers of this group willing to pay a lower price for the same level of environmental quality $Q$. Again the increase in the parameter $\beta$ corresponds to the individual preferences more and more stonger in terms of the environmental quality of housing.

In its turn, the condition $H^{\prime \prime} 2$ means that in the space $(S, P)$ for a given level of $Q$, the slopes of the bid curves are ordered in decreasing order of the parameter $\beta$ : on the right of the intersection of two bid curves, consumers of the group with a higher parameter $\beta$ willing to pay a lower price for the

housing is mathematically equivalent to the case $\underline{H^{\prime} 2}$, and is not studied here since our problematic deals with environmental valuation. 
same level of intrinsic quality $S$, and on the left of the intersection those consumers willing to pay a stronger price.

From the economic point of view, conditions $\underline{H^{\prime \prime} 1}$ and $\underline{H^{\prime \prime} 2}$ mean a kind of subsituabilité between housing characteristics which is more or less strong according to the values of $\beta .^{9}$ As about housing "outside the environmental quality" with $Q=0$ and housing "outside the intrinsic quality" with $S=0$, each group has its specific valuation of those housing:

$$
\begin{aligned}
& E\left(0, S \mid \beta_{i}, u_{i}\right) \neq E\left(0, S \mid \beta_{j}, u_{j}\right), \text { if } \beta_{i} \neq \beta_{j} \\
& E\left(Q, 0 \mid \beta_{i}, u_{i}\right) \neq E\left(Q, 0 \mid \beta_{j}, u_{j}\right), \text { if } \beta_{i} \neq \beta_{j}
\end{aligned}
$$

\section{Implications}

The Spence-Mirrlees conditions imply that two arbitrary bid surfaces of the two different groups, have only one intersection curve.

Definition 3. The intersection curve of two groups $i$ and $j$ is a locus of the points $(q, s)$ such that:

$$
E_{i}\left(q, s \mid \beta_{i}, u_{i}^{\left(k_{i}\right)}\right)=E_{j}\left(q, s \mid \beta_{j}, u_{j}^{\left(k_{j}\right)}\right)
$$

(6) defines implicitly the equation of the intersection curve, noted $s=g_{i j}(q)$.

Proposition 1. A) Under assumptions $H^{\prime} 1$ and $H^{\prime} 2$, the intersection curve between two groups $i$ and $j$ is a vertical line $q=\tilde{Q}_{i j}$.

B) Under assumptions $H^{\prime \prime} 1$ and $H^{\prime \prime} 2$, the intersection curve of the groups is a strictly monotone function in the plan $(Q, S)$.

Proof. A) Immediately from single-crossing conditions $H^{\prime} 1$ and $H^{\prime} 2$.

B) Immediately from sigle-crossing conditions $H^{\prime \prime} 1$ and $H^{\prime \prime} 2$.

\subsection{Sellers behavior}

Following Baudry and Maslianskaïa-Pautrel (2011a, b) we assume the shortrun case of the Rosen (1974) hedonic model, where supply is supposed fixed. This assumption is consistent with existent empirical hedonic studies. We assume that housing attributes are distributed on intervals $\left[0 ; Q_{\max }\right]$ and $\left[0 ; S_{\max }\right]$ with a joint density function $\varphi(Q, S) .{ }^{10}$

\footnotetext{
${ }^{9}$ The case of complementarity of the two housing attributes corresponding to the same sign of derivatives with respect to $\beta$, is not considered in this paper and is a way of future research.

${ }^{10}$ To simplify the notation and calculations, we assume without loss of generality that $Q_{\min }=0$ and that $S_{\min }=0$.
} 
Moreover, unlike the model of Rosen, sellers are assumed to be homogeneous. Thus the sellers' bid functions are identical and correspond to the price function that represents, in a general case, a lower envelope of sellers' bid functions.

Finally we assume that supply is completed by "outside the market" alternative:

Definition 4. "Outside the market" alternative is defined by:

$$
P(h(0,0 \mid \beta))=P(0)=0, \quad \forall \beta .
$$

It is always possible to obtain zero housing characteristics for the price $\mathrm{P}=0^{11}$.

Given the assumptions regarding the housing supply, utility maximization problem of each seller $v$ is equivalent to maximizing of the selling price of her housing characterized by a level of service $H_{v}=h\left(Q_{v}, S_{v}\right)$ :

$$
\forall v, \forall H_{v} \quad \max P_{v}\left(H_{v}\right)
$$

\subsection{Definition of equilibrium}

In the traditional hedonic model, the equilibrium on the housing market is defined if there is a function $p(\mathbf{h})$ such that the distribution of housing demand and the distribution of housing supply are equal

$$
Q^{d}(\mathbf{h})=Q^{s}(\mathbf{h}) \forall \mathbf{h},
$$

and buyers and sellers have an optimal behavior.

In the segmentation model buyers form homogeneous groups of non-zero weight, thus sellers have to take into consideration buyers' behavior when define their selling prices. In particular two types of constraints must be consider for each buyer: participation and incentive constraints. The first type concerns the effective participation of the buyer to the market, that is her arbitrage condition between buying a home and choosing the alternative "outside the market". The second type of constraints concerns different alternatives met by the consumer on the market and it is the arbitrage condition between the purchase of particular dwelling and the purchase of another dwelling on the market. Therefore, hedonic equilibrium of the segmentation model is defined as:

Definition 5 (Hedonic equilibrium of the segmentation model.). Under the assumption of optimizing behavior of buyers and sellers, the market equilibrium is reached when the following three conditions are satisfied:

\footnotetext{
${ }^{11}$ The definition assumes that the "outside the market" alternative does not depend on the type of housing differentiation, or the nature of consumers heterogeneity.
} 
Condition 1 (participative constraint): Each buyer a prefer purchase a $d$ welling rather than "outside the market" alternative:

$$
\forall a, \quad V\left(H_{a}, P^{*}\left(H_{a}\right), R \mid \beta_{a}\right) \geq V\left(0,0, R \mid \beta_{a}\right), \quad H_{a} \in D h
$$

Condition 2 (incentive constraints): For unchanged prices, each buyer is better off with the house she buys than with the houses bought but other buyers:

$$
\forall a, \quad V\left(H_{a}, P^{*}\left(H_{a}\right), R \mid \beta_{a}\right) \geq V\left(H^{\prime}, P^{*}\left(H^{\prime}\right), R \mid \beta_{a}\right), \quad \forall H^{\prime} \in D h,
$$

Condition 3 (maximal extraction of surplus): None of the sellers, $v$, is able to find a buyer at a higher price:

$$
\begin{gathered}
\forall v, \quad P_{v}\left(H_{v}\right)=\max _{\substack{a \in\{A\}, k: u_{a}^{k} \in D U_{a}}} E_{a}^{k}\left(H_{v} \mid R, u_{a}^{k}\right) \\
\end{gathered}
$$

The set of prices $P^{*}$ resulting from this optimization program characterizes the hedonic price function:

Definition 6. Hedonic price. For any level of the index $H$ of housing services, the hedonic price yields the highest of the individual bids where each individual bid function is defined in reference to the house bought by the individual and the associated market equilibrium price:

$$
\forall H \quad P(H)=\max _{u_{a}^{(k)} \in D U_{a}} E_{a}^{*}\left(H \mid R, u_{a}^{(k)}\right) .
$$

In the case of horizontal differentiation, the hedonic equilibrium definition $[5$ becomes:

$$
\begin{aligned}
& \forall i \in\{1, \ldots, N\} \\
& \max _{u^{(i)}} E_{i}\left(q, s \mid \beta_{i}, u^{(i)}\right),(q, s) \in\left[Q_{i-1}, Q_{i}\right] \times\left[S_{i-1}, S_{i}\right] \\
& \text { s.c. } \\
& V\left(h\left(q, s \mid \beta_{i}\right), E_{i}\left(q, s \mid \beta_{i}, u^{(i)}\right)\right) \geq V(0,0) \\
& V\left(h\left(q, s \mid \beta_{i}\right), E_{i}\left(q, s \mid \beta_{i}, u^{(i)}\right)\right) \geq V\left(h\left(\tilde{q}, \tilde{s} \mid \beta_{i}\right), E_{j}\left(\tilde{q}, \tilde{s} \mid \beta_{j}, u^{(j)}\right)\right), \\
& \forall j \neq i,(\tilde{q}, \tilde{s}) \in\left[Q_{j-1}, Q_{j}\right] \times\left[S_{j-1}, S_{j}\right] \\
& \int_{S_{i-1}}^{S_{i}} \int_{Q_{i-1}}^{Q_{i}} \varphi(q, s) \mathrm{d} q \mathrm{~d} s=\eta_{i}
\end{aligned}
$$

The equation (17) means that the market share of a group $i$ is equal to its weight. 
Definition 7. The group $i$ participative constraint corresponds to the bid surface for which the participative constraint introduced by the inequality (15) is saturated. This bid surface is denoted $C P_{i}$ and defined implicitly from the equation:

$$
V\left(h\left(q, s \mid \beta_{i}\right), C P_{i}\left(q, s \mid \beta_{i}, u_{i}^{(C P)}\right)\right)=V(0,0)
$$

Definition 8. The group $i$ incentive constraint with respect to the group $j$ corresponds to the bid surface of the group $i$ for which its incentive constraint (16) with respect to the group $j$ is saturated. This bid surface is denoted $C I_{i j}^{k_{i j}}\left(q, s \mid \beta_{i}, u_{i}^{\left(k_{i j}\right)}\right)$ and defined implicitly from the equation:

$$
\begin{aligned}
& V\left(h\left(q, s \mid \beta_{i}\right), C I_{i j}^{\left(k_{i j}\right)}\left(q, s \mid \beta_{i}, u_{i}^{\left(k_{i j}\right)}\right)\right)=V\left(h\left(\tilde{q}, \tilde{s} \mid \beta_{i}\right), E_{j}^{k_{j}}\left(\tilde{q}, \tilde{s} \mid \beta_{j}, u_{j}^{\left(k_{j}\right)}\right)\right), \\
& (q, s) \in\left[Q_{i-1}, Q_{i}\right] \times\left[S_{i-1}, S_{i}\right],(\tilde{q}, \tilde{s}) \in\left[Q_{j-1}, Q_{j}\right] \times\left[S_{j-1}, S_{j}\right] .
\end{aligned}
$$

\section{Existence of hedonic equilibrium}

As in the vertical differentiation case (see Baudry and Maslianskaïa-Pautrel, 2011a), it is easy to show that the following equilibrium properties are verified :

Proposition 2. If in equilibrium the individual $A$ from group $i$ buys a house with housing services level $H_{A}^{*}=h\left(Q_{A}^{*}, S_{A}^{*} \mid \beta_{i}\right)$ for the price $P_{A}^{*}=$ $E_{i}^{*}\left(H_{A}^{*} \mid \beta_{i}, u_{i}^{*}\right)$. Thus:

$$
\begin{aligned}
& P_{j}\left(H_{j}^{*}\right)>E_{i}^{*}\left(H_{j}^{*} \mid \beta_{i}, u_{i}^{*}\right), \quad \forall j: \beta_{j} \neq \beta_{i} ; \\
& P_{B}\left(H_{B}^{*}\right)=E_{j}^{*}\left(H_{B}^{*} \mid \beta_{i}, u_{i}^{*}\right), \quad \forall B: \beta_{B}=\beta_{A}=\beta_{i}
\end{aligned}
$$

Proof. The proof is immediate from the definition the bid function and the fact that the utility function is increasing with respect to its arguments, which implies an increase in the value of the group's utility following the displacement of the group bid surface down.

The proposition means that : $i$ ) for a group $i$, prices of houses purchased by consumers of other groups can not be located below the equilibrium bid surface of the group $i$, and ii) prices of houses puchased by consumers of the group i belong the same group?s equilibrium bid surface.

For analyzing the existence of hedonic equilibrium and its characteristics, we proceed in two stages. On the first stage we examine the set of incentive constraints of groups, on the second one, we examine their participative constraints. The existence of equilibrium depends on groups preferences namely on different assumptions Spence-Mirrlees presented above. 


\subsection{Incentive constraints}

Consider the iso-cost curves of the groups' bid functions in the space $(Q, S)$. By definition of the group's bid function, the housing services level along the iso-cost curve is constant. Therefore, the iso-cost curves coincide with the curves of iso-index of the housing services (later called, " the iso-H curves"). Given the assumptions about the function $H=h(Q, S \mid \beta)$, the iso- $\mathrm{H}$ curves are convex and decreasing in the plane $(Q, S)$ and an increased level of $H$ moves the iso-H curve upward. Therefore, a iso-H curve of a group, located higher than an other one corresponds to a higher level of utility, ceteris paribus.

Proposition 3. At equilibrium, the curves of iso- $H$ are ordered in the plane $(Q, S)$ in increasing order of $\beta$ from left to right along the axis of $Q$.

Proof. The proof is provided in the appendix B.1.

Theorem 1. At equilibrium, only the incentive constraints with respect to adjacent groups are saturated. ${ }^{12}$

Demonstration. The demonstration of this theorem is provided in the appendix B.2.

Definition 9. The boundary between two groups $i$ and $j$ is the curve of intersection of the equilibrium groups bid surfaces.

Corollary 1. At equilibrium the hedonic price function is continuous.

Proof. The result follows immediately from the proposition 2 and the theorem 1

At equilibrium the boundary $s=g_{i, i-1}(q)$ between groups $i$ and $i-1$ has the follow property:

Proposition 4. A) Under assumptions $H^{\prime} 1$ boundary between groups $i$ and $i-1$ becomes:

$$
q=Q_{i, i-1}
$$

where $Q_{i, i-1}$ is the value of the environmental quality on the boundary between groups $i$ and $i-1$ when $s=0$, and the boundary is the vertical line parallel to the axis $S$.

\footnotetext{
${ }^{12}$ The result of the theorem 1 can be viewed as symmetric to the result of the Boundary indifference lemma in the Epple and Platt (1998, p. 28, lemma 1) sorting model, in that Epple and Platt study the case of a continuous heterogeneity on the demand side and discrete heterogeneity on the supply side, while we study the case of a discrete heterogeneity on the demand side and a continuous heterogeneity on a supply side
} 
B) Under assumptions (H'1" $-H^{\prime \prime}$ the boundary between two groups $s=g_{i, i-1}(q)$ is an increasing function in $q$.

Proof. Follows from proposition 1 .

To determine equilibrium, we should now to show which group(s) fulfills its (their) participative constraint(s) at equilibrium.

\subsection{Group's participative constraint and iterative construc- tion of equilibrium}

\subsubsection{Case of group identical valuation of "outside the environ- mental quality" housing}

Let study the participative constraints of groups $i$ and $j$ such that $\beta_{i}<\beta_{j}$. Under $\left(H^{\prime} 1\right)$ and $\left(H^{\prime} 2\right)$ conditions, the curve of participative constraints intersection is a line belonging to the $(S, P)$ coordinated plan. ${ }^{13}$

The services level of housing with "outside the environmental quality" does not depend on the preference parameter $\beta$ :

$$
h\left(0, s \mid \beta_{i}\right)=h\left(0, s \mid \beta_{j}\right)
$$

In this case, the single-crossig condition $\underline{H}^{\prime} 1$ involves the in the plan $(Q, P)$, for a given level of $S$, the slopes of the participative constraints of groups are ordered in increasing order of the preference parameter. Since all participative constraints cross when $Q=0$, the surfaces corresponding to participative constraints are located one below other, the participative constraint of the first group being the lowest, and the last group one the highest:

$$
C P_{1}(q, s)<C P_{2}(q, s)<\cdots<C P_{N}(q, s), \forall(q, s) \in\left[0, Q_{\max }\right] \times\left[0, S_{\max }\right] .
$$

In this case, as in the vertical differentiation case (see Baudry and Maslianskaïa-Pautrel, 2011a), at equilibrium the first group stays on its participative constraint untill point $Q_{1}$ (moving along the axis $Q$ according the proposition (4). The point $Q_{1}$ is found from the condition of equality

\footnotetext{
${ }^{13}$ The fact that the curve of participative constraints intersection belongs to the $(S, P)$ coordinated plan the name of $H^{\prime}$ assumption: group identical valuation of "outside the environmental quality" alternative. Indeed, when $Q=0$ :

$$
C P_{i}\left(0, s \mid \beta_{i}, u_{i}^{(C P)}\right)=C P_{j}\left(0, s \mid \beta_{j}, u_{j}^{(C P)}\right)=\bar{u},
$$

where $\bar{u}$ is the utility level achieved by all consumers under the $H^{\prime}$ assumptions.
} 
between the share of supply demanded by the first group and the group's weight (see condition (17) of hedonic equilibrium definition):

$$
\int_{0}^{S_{\max }} \int_{0}^{Q_{1}} \varphi(q, s) \mathrm{d} q \mathrm{~d} s=\eta_{1}
$$

The equilibrium price function for the second group corresponds to its bid function obtained from the incentive constraint of the group 2 with respect to the group 1 on the boundary $q=Q_{1}, s \in\left[0, S_{\max }\right]$ (according the proposition (4). The boundary between the groups 2 and 3 is defined from:

$$
\int_{0}^{S_{\max }} \int_{Q_{1}}^{Q_{2}} \varphi(q, s) \mathrm{d} q \mathrm{~d} s=\eta_{2} .
$$

or equivalently:

$$
\int_{0}^{S_{\max }} \int_{0}^{Q_{2}} \phi(q, s) \mathrm{d} q \mathrm{~d} s=\eta_{1}+\eta_{2}
$$

Proceeding in the same way, we construct the surface of hedonic price equilibrium.

Theorem 2. Under the assumptions $\left(H^{\prime} 1\right)$ and $\left(H^{\prime} 2\right)$, an equilibrium of housing market exists and the resulting hedonic price function is implicitly peace-wise defined by the following equations:

$$
\begin{aligned}
& V\left(h\left(q, s \mid \beta_{1}\right), E_{1}^{*}\left(q, s \mid \beta_{1}, u_{1}^{*}\right)\right)=V(0,0) \\
& V\left(h\left(Q_{i-1}, s \mid \beta_{i}\right), E_{i}^{*}\left(q, s \mid \beta_{i}, u_{i}^{*}\right),\right)=V\left(h\left(q, s \mid \beta_{i}\right), E_{i-1}^{*}\left(Q_{i-1}, s \mid \beta_{i-1}, u_{i-1}^{*}\right)\right) \\
& \int_{0}^{S_{\max }} \int_{0}^{Q_{i}} \varphi(q, s) \mathrm{d} q \mathrm{~d} s=\sum_{1}^{i} \eta_{k}
\end{aligned}
$$

Demonstration. The existence of equilibrium is ensured by the construction described above. The equations (28) - (30) are obtained immediately by the generalization of the above reasoning.

\subsubsection{The case of group specific valuation of "outside the environ- mental quality" and "outside the intrinsic quality" housing}

We turn now to study participative constraints of the groups $i$ and $j$ such that $\beta_{i}<\beta_{j}$ under assumptions $\left(H^{\prime \prime} 1\right)$ and $\left(H^{\prime \prime} 2\right)$. The curve of intersection of those participative constraints does not belong to any coordinate plan, and services levels of housing "outside the environmental quality" and "outside the intrinsic quality" is specific for each group:

$$
h\left(0, s \mid \beta_{i}\right) \neq h\left(0, s \mid \beta_{j}\right) \text { and } h\left(q, 0 \mid \beta_{i}\right) \neq h\left(q, 0 \mid \beta_{j}\right)
$$


Let $F_{i j}\left(q, f_{i j}(q)\right)$ the line of intersection of surfaces $C P_{i}$ and $C P_{j}$. It is defined implicitly by the following equation:

$$
C P_{i}\left(q, f_{i j}(q) \mid \beta_{i}, u^{\left(C P_{i}\right)}\right)=C P_{j}\left(q, f_{i j}(q) \mid \beta_{j}, u^{\left(C P_{j}\right)}\right) .
$$

According to the conditions ( $H^{\prime \prime} 1$ and $\left(H^{\prime \prime} 2\right.$, at the left of the curve $F_{i j}\left(q, f_{i j}(q)\right)$ the participative constraint of the group $i$ is located above the participative constraint of the group $j$, and at the left of the intersection curve the order is reversed:

$$
\begin{array}{ll}
C P_{i}\left(q, s \mid \beta_{i}, u^{\left(C P_{i}\right)}\right)>C P_{j}\left(q, s \mid \beta_{j}, u^{\left(C P_{j}\right)}\right), & \text { if } s>f_{i j}(q) \\
C P_{i}\left(q, s \mid \beta_{i}, u^{\left(C P_{i}\right)}\right)<C P_{j}\left(q, s \mid \beta_{j}, u^{\left(C P_{j}\right)}\right), & \text { if } s<f_{i j}(q)
\end{array}
$$

Proposition 5. Under assumption $\left(H^{\prime \prime} 1\right)$ - $\left(H^{\prime \prime} 2\right)$ and given the independence of the "outside the market" alternative from the preference parameter $\beta$, all participative constraints are crossing in the same curve:

$$
F_{i j}\left(q, f_{i j}(q)\right) \equiv F(q, f(q)), \forall i, j \in\{1,2, \ldots, I\}
$$

Proof. The proof of this proposition is provided in the appendix B.4.

The following proposition defines which group saturates its participative constraint at equilibrium.

Proposition 6. The group $i^{\circ}$ which saturates its participative constraint at equilibrium can be find from the following condition:

$$
i^{\circ}=\min _{i \in\{1, \ldots, I\}} i: \sum_{k=1}^{i} \eta_{k} \geq \Pi(f(q)) .
$$

Proof. The proof is provided in the appendix B.5.

At equilibrium, each group $i<i^{\circ}$, saturates its incentive constraint with respect to the next group passing through the boundary of the group with the next one. Each group $i>i^{\circ}$, saturates its incentive constraint with respect to the previous group passing through the boundary of the group with the previous one. The boundaries can be obtained from condition of equivalence between distribution of supply and distribution of demand of the housing services index. The figure 3 shows different configurations for boundaries between consumers groups. 
Figure 3: Different configurations for consumers groups boundaries
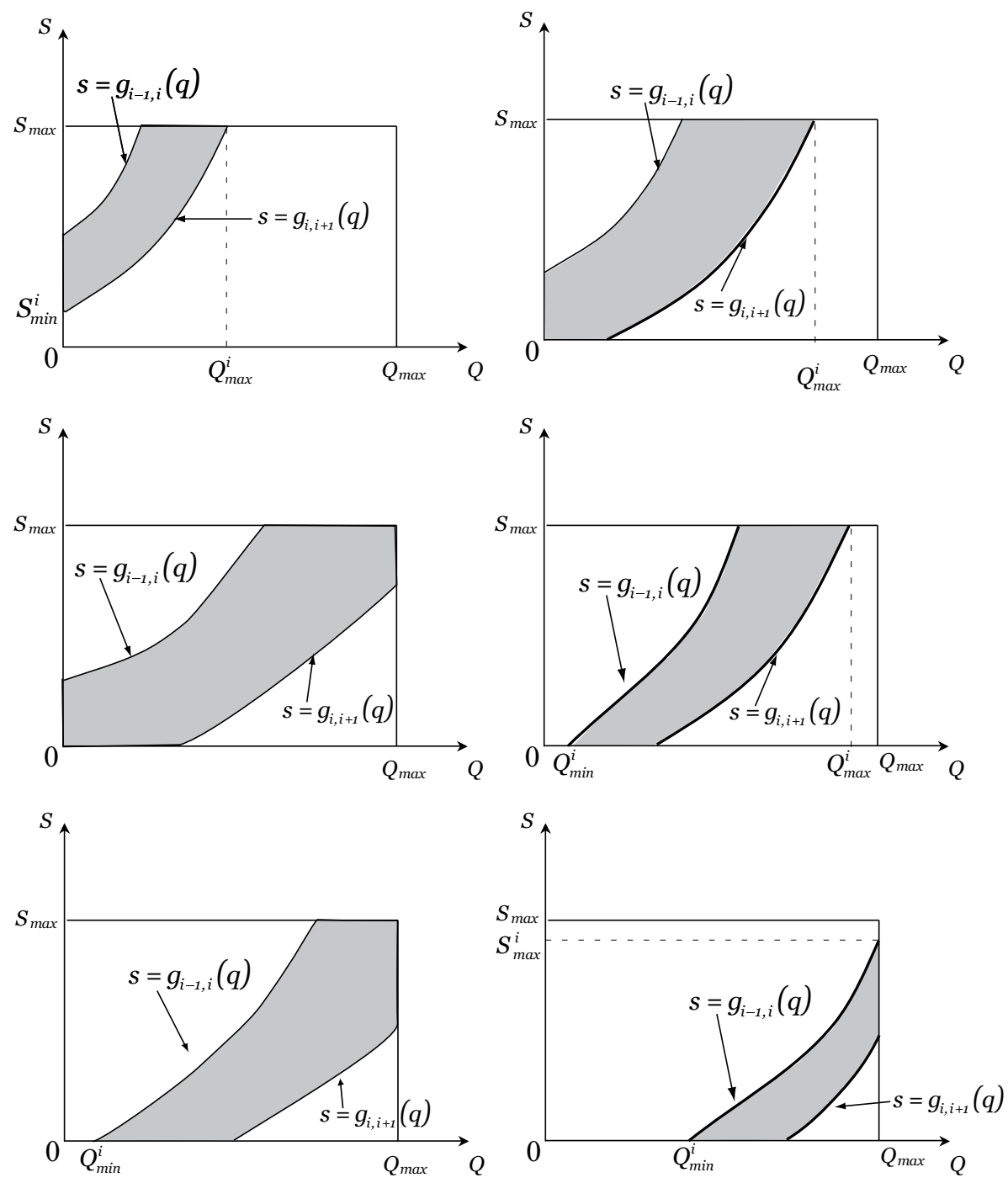

Theorem 3. Under assumption $\left(H^{\prime \prime} 1\right)$ and $\left(H^{\prime \prime} 2\right)$, there is an equilibrium on the housing market for which the hedonic price function corresponds to the equilibrium groups bid surfaces, $E_{i}^{*}\left(q, s \mid \beta_{i}, u_{i}^{*}\right)$, defined from the following 
equations:

$$
\begin{aligned}
& E_{i^{\circ}}^{*}=C P_{i^{\circ}}\left(q, s \mid \beta_{i^{\circ}}, u_{i^{\circ}}^{*}\right), \text { où } \\
& C P_{i^{\circ}}\left(q, s \mid \beta_{i^{\circ}}, u_{i^{\circ}}^{*}\right): V\left(h\left(q, s \mid \beta_{i^{\circ}}\right), C P_{i^{\circ}}\left(q, s \mid \beta_{i^{\circ}}, u_{i^{\circ}}^{*}\right)\right)=V(0,0), \\
& i^{\circ}=\min _{i \in\{1, \ldots, I\}} i: \sum_{k=1}^{i} \eta_{k} \geq \Pi(f(q)), \\
& \quad s=f(q): C P_{i^{\circ}}\left(q, f(q) \mid \beta_{i^{\circ}}, u_{i^{\circ}}^{*}\right)=C P_{i}\left(q, f(q) \mid \beta_{i}, u_{i}^{(C P)}\right), i \in\{1, \ldots, I\} \backslash\left\{i^{\circ}\right\} \\
& \Pi(f(q))=\left[\begin{array}{l}
\int_{0}^{S_{\max }} \int_{0}^{f^{-1}(s)} \varphi(q, s) \mathrm{d} q \mathrm{~d} s, \quad \text { if } S_{\max } \leq Q_{\max } ; \\
\int_{0}^{f\left(Q_{\max }\right)} \int_{0}^{f^{-1}(s)} \varphi(q, s) \mathrm{d} q \mathrm{~d} s \\
+\int_{f\left(Q_{\max }\right)}^{S_{\max }} \int_{0}^{Q_{\max }} \varphi(q, s) \mathrm{d} q \mathrm{~d} s, \quad \text { if } S_{\max }>Q_{\max }
\end{array}\right. \\
& \forall 1 \leq i<i^{\circ}: \\
& V\left(h\left(q, s \mid \beta_{i}\right), E_{i}^{*}\left(q, s \mid \beta_{i}, u_{i}^{*}\right)\right)=V\left(h\left(q, g_{i, i+1}(q) \mid \beta_{i}\right), E_{i+1}^{*}\left(q, g_{i, i+1}(q) \mid \beta_{i+1}, u_{i+1}^{*}\right)\right),
\end{aligned}
$$

$\forall i^{\circ}<i \leq I$ :

$$
V\left(h\left(q, s \mid \beta_{l}\right), E_{l}^{*}\left(q, s \mid \beta_{l}, u_{l}^{*}\right)\right)=V\left(h\left(q, g_{l-1, l}(q) \mid \beta_{l}\right), E_{l-1}^{*}\left(q, g_{l-1, l}(q) \mid \beta_{l-1}, u_{l-1}^{*}\right)\right),
$$

$$
\begin{aligned}
& \forall i, s=g_{i, i+1}(q): \\
& E_{i}^{*}\left(q, g_{i, i+1}(q) \mid \beta_{i}, u_{i}^{*}\right)=E_{i+1}^{*}\left(q, g_{i, i+1}(q) \mid \beta_{i+1}, u^{(i+1)}\right) \\
& \sum_{k=1}^{i} \Pi_{i}\left(g_{i, i+1}(q)\right)=\sum_{k=1}^{i} \eta_{i}, i \in\{1, \ldots, I\}, \text { where } \\
& \sum_{k=1}^{i} \Pi_{i}\left(g_{i, i+1}(q)\right)=\left[\begin{array}{l}
\int_{S_{\min }^{i}}^{S_{\max }} \int_{Q_{\min }^{i}}^{g_{i, i+1}^{-1}(s)} \varphi(q, s) \mathrm{d} q \mathrm{~d} s, \text { if } S_{\max } \leq Q_{\max } \\
\int_{S_{\min }^{i}}^{g_{i, i+1}\left(Q_{\max }\right)} \int_{Q_{\min }^{i}}^{g_{i, 1}^{-1}(s)} \varphi(q, s) \mathrm{d} q \mathrm{~d} s \\
+\int_{g_{i, i+1}\left(Q_{\max }\right)}^{S_{\max }} \int_{0}^{Q_{\max }} \varphi(q, s) \mathrm{d} q \mathrm{~d} s, \text { if } S_{\max }>Q_{\max }
\end{array}\right.
\end{aligned}
$$

The segments limits are defined from the equations (B.38)-(B.41).

Demonstration. The existence of equilibrium is ensured by the condition (B.42) of the proposition [6] and by the property of the density function on the supply side $\left(\int_{0}^{S_{\max }} \int_{0}^{Q_{\max }} \varphi(q, s) \mathrm{d} q \mathrm{~d} s=1\right)$ and the distribution of consumers groups weights on the demand side $\left(\sum_{i=1}^{N} \eta_{i}=1\right)$. 
The demonstration of the hedonic price function equations resulting from the equilibrium is immediate by the construction described above.

\subsection{Implicit prices of housing attributes and sorting of the demand for housing attributes}

\subsubsection{Case of group identical valuation of "outside the environ- mental quality" housing}

The theorem 2 establishes the existence of equilibrium and its equations under the single-crossing assumption $H^{\prime} 1$ and $H^{\prime}$. As in the vertical differentiation case, the hedonic price function resulting from equilibrium is defined by segments corresponding to the groups bid surfaces of equilibrium.

Theorem 4. In the presence of a horizontal differentiation of housing, an consumers heterogeneity by groups of preferences for housing attributes, and under the assumptions ( $\underline{H}^{\prime} 1$ and $\left(\underline{H^{\prime}} 2\right)$, the implicit price of environmental quality has discontinuities on the boundaries between the segments of the hedonic price function.

Demonstration. The demonstration of the theorem is provided in the appendix B.3.

As in the case of vertical differentiation, consumers of the $1^{\text {st }}$ group (which the lowest parameter of preferences for environmental quality) buy at equilibrium the housing with minimal level of environmental quality (according to the proposition 3), involving a complete sorting of the environmental quality demand.

\subsubsection{Case of group specific valuation of "outside the environ- mental quality" and "outside the intrinsic quality" housing}

Theorem 3 establishes the existence of equilibrium and its equations under assumptions of single-crossing ( $H^{\prime \prime} 1$ and $\left(H^{\prime \prime} 2\right.$. As in the previous case of group identical "outside the environmental quality" alternative, in the case of group specific alternatives "outside the one or other housing attributes", the equilibrium hedonic price function is piecewise defined, and each segment corresponds to the equilibrium groups bid surfaces. However, as to the result about the discontinuity of the marginal hedonic price function, in this case it becomes:

Theorem 5. In the presence of a horizontal differentiation of housing and a group-wise buyers heterogeneity of the preferences for housing attributes, and under the assumptions ( $H^{\prime \prime} 1$ ) and $\left(H^{\prime \prime} 2\right.$, the implicit price of environmental quality and the implicit price of intrinsic attribute have discontinuities on the boundaries between the segments of the hedonic price function. 
Demonstration. The demonstration of this theorem is provided in the appendix B.6.

However, unlike the previously studied case, it is possible now that several groups buy at equilibrium housing with the minimum environmental quality. In addition, when such situation exists, the participative constraint of the $1^{\text {st }}$ group is not saturated at equilibrium. The condition of saturation of the participative constraint is not no longer the condition of the minimum level of parameter heterogeneity, but the relationship between the weight of first groups and the market share of the supply available for these groups to the left of the intersection of groups participative constraints. So this is not necessarily the group with the parameter of preferences $\beta$ the lowest which the sellers extract the entire consumer surplus. This result can affect the valuation of the change in welfare following a modification of the environmental quality of housing, and therefore the environmental cost-benefit analysis.

Figure 4: Partial sorting of housing attributes demand

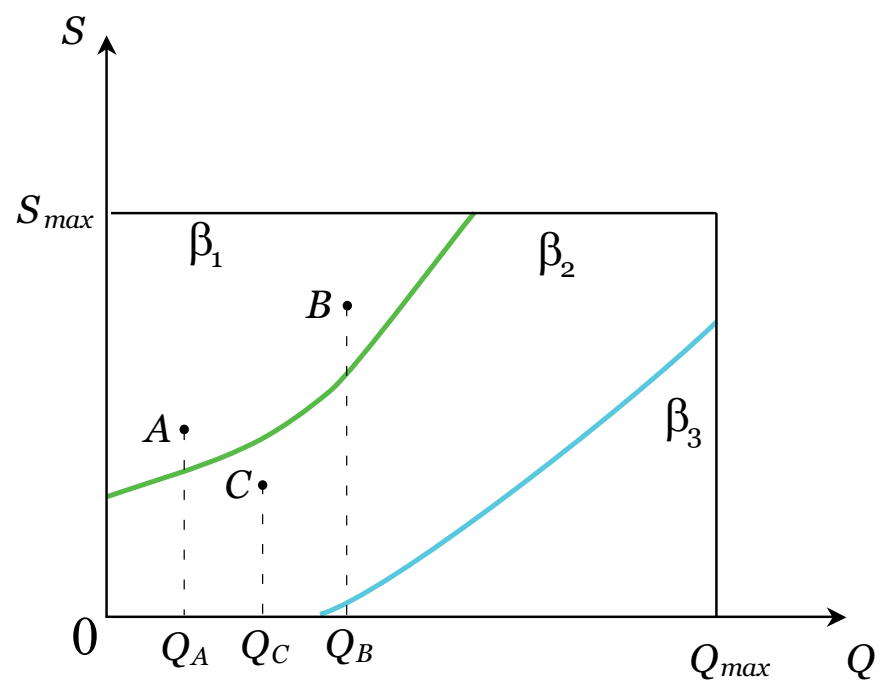

In the case of a horizontal differentiation with group specific "outside the one or other housing attributes" alternatives (assumptions $H^{\prime \prime}$ ), the market equilibrium leads to a partial sorting of housing attributes demand by consumers groups. The figure 4 illustrates this point: the consumers $A$ and $B$ belong to the group with the preference parameter $\beta_{1}$ and the consumer $C$ belongs to the group with the preference parameter $\beta_{2}\left(\beta_{1}<\beta_{2}\right)$, however, $Q_{A}<Q_{C}<Q_{B}$. This result can be consider as dual to the two dimensions stratification result obtained by Epple and Platt (1998), and concerning the 
income and preference parameter partial stratification at equilibrium of the sorting model.

\section{Numerical application to the case of nested CES direct utility function}

\subsection{Case of group identical valuation of "outside the envi- ronmental quality" housing}

The figures [5] and [6 show numerical illustrations done for a nested CES utility function:

$$
\begin{aligned}
& U\left(h\left(q, s \mid \beta_{j}\right), X\right)=\left[\alpha h\left(q, s \mid \beta_{j}\right)^{\sigma}+(1-\alpha) X^{\sigma}\right]^{\frac{1}{\sigma}}, \\
& h\left(q, s \mid \beta_{j}\right)=\left[\beta_{j} q^{\sigma}+s^{\sigma}\right]^{\frac{1}{\sigma}} \\
& \sigma \in] 0,1[, \alpha \in[0,1[.
\end{aligned}
$$

For numerical simulations, we use the case of three groups of individuals according to their preferences parameter $\beta$ with $\beta_{1}=0.1$ (low preference for the environmental quality of housing), $\beta_{2}=0.5$ (average preference for the environmental quality of housing), $\beta_{3}=0.7$ (strong preference for the environmental quality of housing). We consider one case of uniform distribution of the size of consumer groups $\eta_{1}=\eta_{2}=\eta_{3}=0.3(3)$ and one case where the group 2 is larger than the other two groups: $\eta_{1}=0.2, \eta_{2}=0.6, \eta_{3}=0.2$. Consumers' income is the average of the log-normal distribution constructed on data from the Loire estuary area, and equal to 19 900. We chose the parameters $\alpha=0.4$ and $\sigma=0.7$. The joint distribution of housing attributes is assumed to be uniformly distributed on the intervals $[0,15000] \times[0,9000]$.

Figure 5: Hedonic price function with different relative weights of consumers groups with heterogeneous preferences
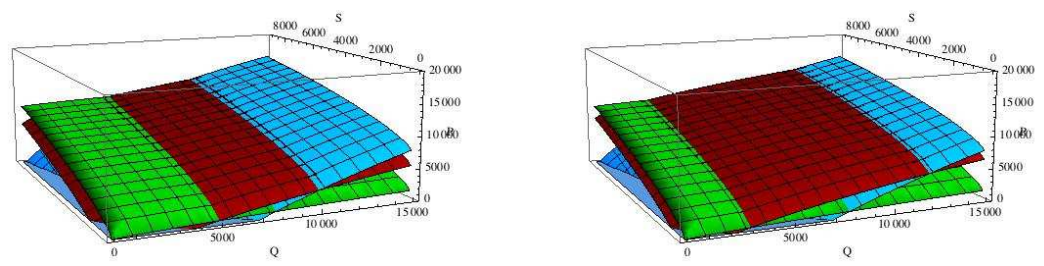

(a) Hedonic price. Identical weights of (b) Hedonic price. Different weights of consumers groups. consumers groups.

The graphs confirm the theoretical results. The hedonic price is the envelope surface of the groups' bid surfaces (figures [5](a)] and [5](b)]. Differences in the group weights have an impact on the share of environmental quality acquired by each group. In the case where the weights are the same, the share of environmental quality acquired by each group are identical (Figure 
Figure 6: Implicit prices of housing attributes in the case of group identical "outside the environmental quality" alternative.

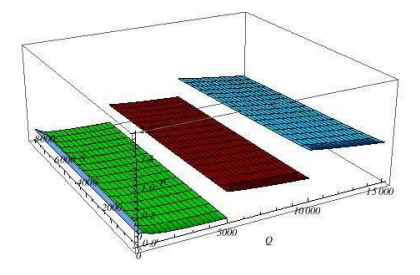

(a) Implicit price of the housing environmental quality.

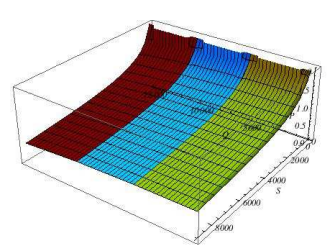

(b) Implicit price of the housing intrinsic quality.

[5)(a). In the case where the weight of the $2^{\text {nd }}$ group is more important the environmental quality demanded by this group is also higher (figure 5](b)) . Figure [6 shows implicit prices of each housing attribute. The implicit price of environmental quality is a discontinuous function on the borders of the segments (figure 6[(a)]. However, the implicit price of intrinsic housing quality is a continuous function on the domain of possible attributes of housing (Figure G(b)].

\subsection{Case of group specific valuation of "outside the envi- ronmental quality" and "outside the intrinsic quality" housing}

As in the previous section, we illustrates the obtained results in making a numerical simulation with a nested CES direct utility function:

$$
\begin{aligned}
& U\left(h\left(q, s \mid \beta_{j}\right), X\right)=\left[\alpha h\left(q, s \mid \beta_{j}\right)^{\sigma}+(1-\alpha) X^{\sigma}\right]^{\frac{1}{\sigma}}, \\
& h\left(q, s \mid \beta_{j}\right)=\left[\beta_{j} q^{\sigma}+\left(1-\beta_{j}\right) s^{\sigma}\right]^{\frac{1}{\sigma}}, \\
& \sigma \in] 0,1[, \alpha \in[0,1[.
\end{aligned}
$$

The equilibrium equations in the case of the nested CES utility function (46) - (47) are obtained in the appendix [C] The figure 7 shows the hedonic price function as well as implicit prices of the housing attributes for the numerical application.

The simulations are carried for the same parameters of the utility function and the same consumer income, as in the previous case: $\alpha=0.4$, $\sigma=0.7$ and $\mathrm{R}=19$ 900. The preference parameters of the three groups are also identical to the previous case ones: $\beta_{1}=0.1, \beta_{2}=0.5, \beta_{3}=0.7$. The groups weights are respectively: $\eta_{1}=0,17, \eta_{2}=0,74, \eta_{3}=0,09$. the joint distribution of housing attributes is supposed uniform distribution on the intervals $[0,1000] \times[0,1500]$.

The hedonic price is the envelope surface of groups' bid surfaces (graph [4[a)], but this is participative constraint of the $2^{\text {nd }}$ group is saturated. The 
Figure 7: Hedonic price function and implicit prices under assumption $H^{\prime \prime}$. Application for a nested CES function

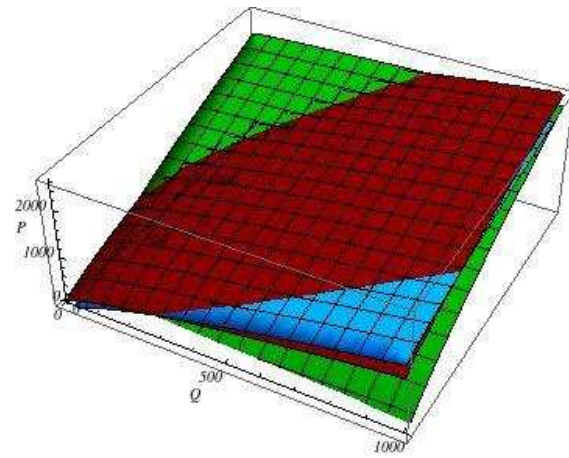

(a) Hedonic price function.

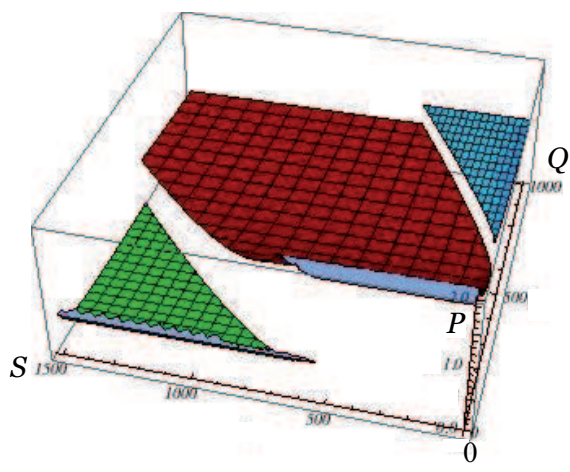

(c) Implicit price of the environmental (d) quality.

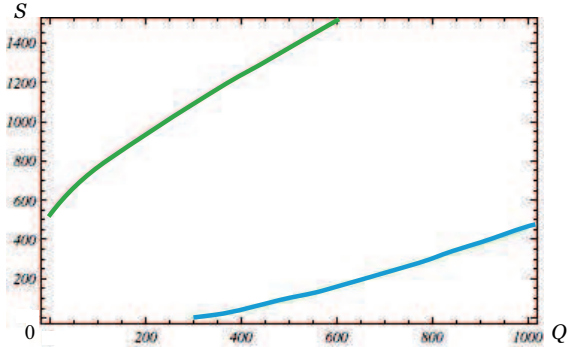

(b) Boundaries between groups (projection).

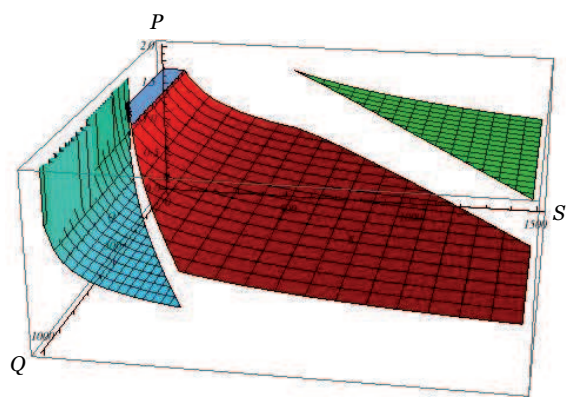

(d) Implicit price of the intrinsic attribute.

graph [7(b) represents the boundaries between consumer groups in the plane $(Q, S)$. The implicit price of environmental quality and the intrinsic attribute are discontinuous on the boundaries of the segments (graphs [4](c)

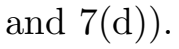




\section{Conclusion}

The theoretical model developed in this paper shows how group-wise heterogeneity on the demand side influence the equilibrium of housing market with horizontal differentiated supply and the formation of the hedonic price function. It complete the hedonic segmentation analysis of Baudry and Maslianskaïa-Pautrel (2011a, b) for vertical differentiation of housing supply by investigating the more realistic case of horizontal differentiation. So both models appear as a third type of modeling underlying hedonic environmental assessment besides the " traditional" hedonic model of Rosen (1974) and "new" hedonic or sorting models, developed among others, by Epple and Platt (1998); Epple and Sieg (1999); Kuminoff (2009). While the first considers the formation of an equilibrium in the market for differentiated products by assuming a continuous heterogeneity on the demand side and a continuous distribution on the supply side, and the latter examines the allocation of a continuum individuals with a continuous heterogeneity between a discrete number of communities (each characterized by an homogeneous amenities provision and housing prices in the same community), our model examines the implications of (discrete) heterogeneity by consumer groups in the presence of a continuous distribution on the supply side.

Following Baudry and Maslianskaïa-Pautrel (2011a b), we based on the theoretical framework of Rosen model assuming that the supply side distributions of two housing attributes (environmental quality and intrinsic quality) are fixed. This assumption is consistent with the short-term assumption observed in empirical hedonic models. Each house is characterized by a level of housing services that aggregates the two housing attributes. Contrarily to Baudrv and Maslianskaïa-Pautrel (2011a,b), there is an horizontal differentiation of housing that is the aggregate function differs from one consumer group to another. The nature of horizontal differentiation changes depending on whether the consumers value the same way or not the alternatives "outside the environmental quality" and "outside the intrinsic quality". We studied in this paper the two following configurations: group identical alternative "outside the environmental quality" and group specific for each alternatives.

Our main results are threefold. First, we confirm the Baudry and Maslianskaïa -Pautrel (2011a, b) result that the group-wise consumers heterogeneity leads to a segmentation of the hedonic price function in the housing market equilibrium. Hedonic price function is continuous, but build of different segments corresponding to each consumer group. As well as in the vertical differentiation case, this result has two major implications for the "usual" estimation procedure developed from the model of Rosen. On the one hand, the hedonic price function we obtain, based on individual characteristics, while in the "usual" procedure, individual characteristics appear only on the second stage, once the hedonic price function estimated. On the other 
hand, the segmentation of the hedonic price function implies a discontinuity of the implicit price of environmental quality of housing on the borders of the segments, which invalidates the second stage of the procedure where the implicit price function is assumed continuous.

Our second results concern sorting of the consumers demand. We demonstrate that the identical valuation of the "out of environmental quality" alternative leads, as in the vertical differentiation case, to complete sorting of the demand for the housing environmental attribute. However, in the case of group specific valuation of housing without environmental or intrinsic quality, the segmentation of hedonic price function leads to partial sorting of the demand for housing attributes by consumers groups. This result can be viewed as dual to the partial two-dementional stratification by consumer income and preferences in sorting models (Epple and Platt, 1998).

Finally, our third result deals with consumers surplus extraction in equilibrium. Fixed supply and short-run assumption lead to sellers of a part of housing, extract at equilibrium, the all consumer surplus of one or more groups. We show that in the case of group specific valuation of housing without environmental or intrinsic quality, the group with the lowest parameter for environmental quality is not necessarily the one with the whole surplus extracted. In the case of group identical valuation, as in the vertical differentiation case, the whole surplus is extracted from the first consumers group that is with the lowest preference parameter. Thus the segmentation have implications for the assessment of welfare related to changes in environmental quality, and thus for the cost-benefice environmental analysis. The study of these implications constitutes one of the future research.

This article calls for more investigations.

From the theoretical point of view, it could be interesting to study a mixed case with consumers continuous heterogeneity in income and groupwise heterogeneity by housing attributes preferences. This would remove the strong assumption of equality of income among individuals in the presence of an horizontal differentiation of housing.

From the empirical point of view, this paper develops the basic modeling on which econometric methods alternative to the "usual" two stage procedure should be based for correctly deal with aspects of the housing market segmentation. 


\section{Appendices}

\section{A Three approaches of the hedonic theory}

Figure 8: Three approaches of the hedonic theory

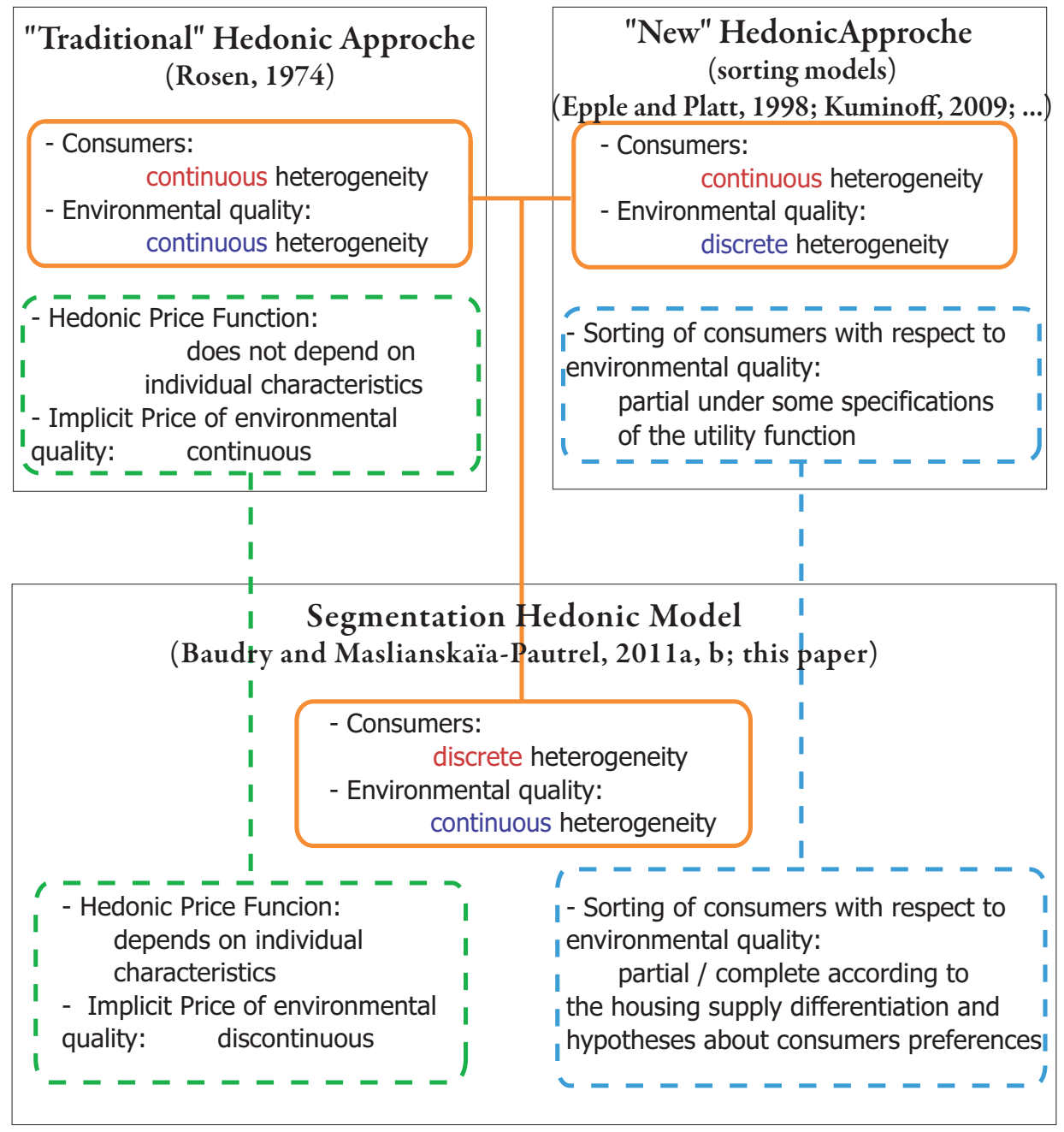




\section{B Proofs and demonstrations}

\section{B.1 Proof of the proposition 3}

Let two iso-H curves on the plan $(Q, S)$, corresponding to the same housing services level $\tilde{h}$, of groups $i$ and $j$ such that $\beta_{i}<\beta_{j}$ :

$$
\begin{aligned}
& s=\tilde{s}_{i}\left(q \mid \beta_{i}\right): h\left(q, \tilde{s}_{i}\left(q \mid \beta_{i}\right) \mid \beta_{i}\right)=\tilde{h} ; \\
& s=\tilde{s}_{j}\left(q \mid \beta_{j}\right): h\left(q, \tilde{s}_{j}\left(q \mid \beta_{j}\right) \mid \beta_{j}\right)=\tilde{h} .
\end{aligned}
$$

Let $\left(q^{*}, s^{*}\right)$ the intersection point of $\tilde{s}_{i}$ and $\tilde{s}_{j}$.

We assume that at equilibrium there exists $\left(q_{i}^{\prime}, s_{i}^{\prime}\right) \in \tilde{s}_{i}(\cdot)$ et $\left(q_{j}^{\prime}, s_{j}^{\prime}\right) \in$ $\tilde{s}_{j}(\cdot)$ such that:

$$
\left\{\begin{array}{c}
q_{j}^{\prime}<q^{*}<q_{i}^{\prime} \\
s_{j}^{\prime}>s^{*}>s_{i}^{\prime}
\end{array}\right.
$$

This condition means that the iso-H curve of the group with higher level of $\beta$ is located on the left of the iso-H curve of the group with lower level of $\beta$.

Since $\beta_{i}<\beta_{j}$, it follows that $s_{j}^{\prime}=\tilde{s}_{j}\left(q_{j}^{\prime} \mid \beta_{j}\right)>\tilde{s}_{i}\left(q_{i}^{\prime} \mid \beta_{i}\right) \doteq s_{i}^{\prime \prime}$. Consequently, the point $\left(q_{j}^{\prime}, s_{j}^{\prime}\right)$ is located above the iso-H curve $\tilde{s}_{i}(\cdot)$ of the group $i$. It means that individuals of the group $i$ could achieve a higher utility level if they are located on the iso-H curve passing through the point $\left(q_{j}^{\prime}, s_{j}^{\prime}\right)$ (the iso- $\mathrm{H}$ curves of both groups correspond to the same price level). The incentive constraint is not satisfied and thus the condition (B.3) is not satistied at equilibrium.

Consequently, at equilibrium the iso- $\mathrm{H}$ curves are ordering in the plan $(Q, S)$ in increasing order of $\beta$, from left to the right along the axis $Q$. Q.E.D.

\section{B.2 Demonstration of the theorem [}

$1^{\circ}$. The saturation of incentive constraints with respect to the adjacent groups follows immediately from the proposition 3 . Indeed, suppose that at equilibrium

$$
\begin{gathered}
\left\{\left(\bar{Q}_{i, i+1}^{*}, \bar{S}_{i, i+1}^{*}\right)\right\}=\left\{(q, s):\left(h\left(q, s \mid \beta_{i}\right)=\bar{H}\right) \&\left(E_{i}^{*}\left(\bar{H} \mid \beta_{i}, u_{i}^{*}\right)=P^{*}(\bar{H})\right)\right\} \\
\bigcap\left\{(q, s):\left(h\left(q, s \mid \beta_{i+1}\right)=\bar{H}\right) \&\left(E_{i+1}^{*}\left(\bar{H} \mid \beta_{i+1}, u_{i+1}^{*}\right)=P^{*}(\bar{H})\right)\right\}
\end{gathered}
$$

$\left(\bar{Q}_{i, i+1}^{*}, \bar{S}_{i, i+1}^{*}\right)$ is the intersection point of the iso-H equilibrium curves of the groups $i$ and $i+1$, corresponding to a housing services level $\bar{H}$.

So, $\left.h\left(\bar{Q}_{i, i+1}^{*}, \bar{S}_{i, i+1}^{*}\right) \mid \beta_{i}\right)=h\left(\bar{Q}_{i, i+1}^{*}, \bar{S}_{i, i+1}^{*} \mid \beta_{i+1}\right)$ and $E_{i}\left(\bar{Q}_{i, i+1}^{*}, \bar{S}_{i, i+1}^{*} \mid \beta_{i}, u_{i}^{*}\right)=E_{i+1}\left(\bar{Q}_{i, i+1}^{*}, \bar{S}_{i, i+1}^{*} \mid \beta_{i+1}, u_{i+1}^{*}\right)$. 
Consequently

$$
\begin{aligned}
& \left.V\left(h\left(\bar{Q}_{i, i+1}^{*}, \bar{S}_{i, i+1}^{*}\right) \mid \beta_{i}\right), E_{i}\left(\bar{Q}_{i, i+1}^{*}, \bar{S}_{i, i+1}^{*} \mid \beta_{i}, u_{i}^{*}\right)\right) \\
= & \left.V\left(h\left(\bar{Q}_{i, i+1}^{*}, \bar{S}_{i, i+1}^{*}\right) \mid \beta_{i}\right), E_{i+1}\left(\bar{Q}_{i, i+1}^{*}, \bar{S}_{i, i+1}^{*} \mid \beta_{i+1}, u_{i+1}^{*}\right)\right),
\end{aligned}
$$

and

$$
\begin{aligned}
& \left.V\left(h\left(\bar{Q}_{i, i+1}^{*}, \bar{S}_{i, i+1}^{*}\right) \mid \beta_{i+1}\right), E_{i+1}\left(\bar{Q}_{i, i+1}^{*}, \bar{S}_{i, i+1}^{*} \mid \beta_{i+1}, u_{i+1}^{*}\right)\right) \\
= & \left.V\left(h\left(\bar{Q}_{i, i+1}^{*}, \bar{S}_{i, i+1}^{*}\right) \mid \beta_{i+1}\right), E_{i}\left(\bar{Q}_{i, i+1}^{*}, \bar{S}_{i, i+1}^{*} \mid \beta_{i}, u_{i}^{*}\right)\right),
\end{aligned}
$$

from which $\left(\bar{Q}_{i, i+1}^{*}, \bar{S}_{i, i+1}^{*}\right) \in C I_{i, i+1}^{k_{i, i+1}}$ and $\left(\bar{Q}_{i, i+1}^{*}, \bar{S}_{i, i+1}^{*}\right) \in C I_{i+1, i}^{k_{i j}}$, so $C I_{i, i+1}^{k_{i+1, i}} \equiv$ $E_{i+1}^{*}$ (the incentive constraint of the group $i$ with respect to the group $i+1$ and the incentive constraint of the group $i+1$ with respect to the group $i$ are equilibrium bid surfaces of the groups $i$ and $i+1$ respectively).

$2^{\circ}$. The incentive constraint of the group $i$ with respect to a group $j$ such that: $j \neq i+1, j \neq i_{1}$ could not be saturated at equilibrium because, if they are, the iso-H curves of the groups between $i$ and $j$ do not be monotone.

$1^{\circ}$ and $2^{\circ}$ demonstrate the theorem 1

\section{B.3 Demonstration of the theorem 4}

Let study the part of the hedonic price surface corresponding to a group's $i$ equilibrium bid function. By definition 2 of individual bid function, the equilibrium prices for the group $i$ satisfy:

$$
V\left(h(q, s), P^{*}(q, s)\right)=u_{i}^{*}, \quad(q, s) \in D h_{i}
$$

where $u_{i}^{*}$ is equilibrium reference utility of the group $i$, and $D h_{i}$ is its definition domain equal to $\left[Q_{i-1}, Q_{i}\right] \times\left[0, S_{\max }\right]$.

$1^{\circ}$. The partial derivative of (B.7) with respect to $Q$, gives:

$$
\frac{\partial V}{\partial h} \frac{\partial h}{\partial Q}+\frac{\partial V}{\partial P} \frac{\partial P}{\partial Q}=0
$$

from what

$$
\left.\frac{\partial P}{\partial Q}\right|_{(q, s) \in D h_{i}}=-\left.\frac{\partial V / \partial h \partial h / \partial Q}{\partial V / \partial P}\right|_{(q, s) \in D h_{i}} .
$$

The equation (B.9) is verified for each group $i \in\{1, \ldots, I\}$.

Let study two adjacent groups $i$ and $i+1$. The Spence-Mirrlees condition ( $H^{\prime} 1$, involves: $\frac{\partial}{\partial \beta}\left(\frac{\partial P}{\partial Q}\right)>0$, for all $S$ and $\beta$. Consequently:

$$
\left.\frac{\partial P_{i}^{*}}{\partial Q}\right|_{q=Q_{i}}<\left.\frac{\partial P_{i+1}^{*}}{\partial Q}\right|_{q=Q_{i}},
$$

since $\beta_{i}<\beta_{i+1}$. 
The discontinuity of the implicit price of environmental quality on the boundaries of segments, is thus proven.

$2^{\circ}$. The partial derivative of (B.7) with respect to $S$, give, for each group $i \in\{1, \ldots, I\}$ :

$$
\left.\frac{\partial P}{\partial S}\right|_{(q, s) \in D h_{i}}=-\left.\frac{\partial V / \partial h \partial h / \partial S}{\partial V / \partial P}\right|_{(q, s) \in D h_{i}}
$$

The Spence-Mirrlees condition $\left(\underline{H^{\prime} 2}\right)$, involves that: $\frac{\partial}{\partial \beta}\left(\frac{\partial P}{\partial S}\right)=0$, for all $Q$ and $\beta$. Consequently:

$$
\left.\frac{\partial P_{i}^{*}}{\partial S}\right|_{q=Q_{i}}=\left.\frac{\partial P_{i+1}^{*}}{\partial S}\right|_{q=Q_{i}}, \quad \forall i .
$$

The implicit price of the intrinsic quality is continuous on all definition domain $\left[0, Q_{\max }\right] \times\left[0, S_{\max }\right]$.

$1^{\circ}$ and $2^{\circ}$ demonstrate the theorem 4

\section{B.4 Proof of the proposition 5}

Let study the participative constraints of three groups $i_{1}<i_{2}<i_{3}$ : $C P_{i_{1}}=$ $E_{i_{1}}\left(s, q \mid \beta_{i_{1}}, u^{\left(C P_{i_{1}}\right)}\right), C P_{i_{2}}=E_{i_{2}}\left(s, q \mid \beta_{i_{2}}, u^{\left(C P_{i_{2}}\right)}\right), C P_{i_{3}}=E_{i_{3}}\left(s, q \mid \beta_{i_{3}}, u^{\left(C P_{i_{3}}\right)}\right)$. Since the "outside the market" alternative does not depend on the parameter $\beta$, and by definition of the participative constraint we obtain: $u^{\left(C P_{i_{1}}\right)}=$ $u^{\left(C P_{i_{2}}\right)}=u^{\left(C P_{i_{3}}\right)}=U(R, 0) \doteq u^{0}$.

We adopt the following notations:

$s=f_{12}(q)$ for the intersection curve between the surfaces $C P_{i_{1}}$ and $C P_{i_{2}}$

$s=f_{23}(q)$ for the intersection curve between the surfaces $C P_{i_{2}}$ and $\mathrm{CP}_{i_{3}}$

$s=f_{13}(q)$ for the intersection curve between the surfaces $C P_{i_{1}}$ and $C P_{i_{2}}$.

By definition of the participative constraint

$$
\begin{aligned}
& C P_{i_{1}}\left(q, f_{12}(q) \mid \beta_{i_{1}}, u^{0}\right)=C P_{i_{2}}\left(q, f_{12}(q) \mid \beta_{i_{2}}, u^{0}\right)=F_{12}\left(q, f_{12}(q)\right) \\
& C P_{i_{2}}\left(q, f_{23}(q) \mid \beta_{i_{2}}, u^{0}\right)=C P_{i_{3}}\left(q, f_{23}(q) \mid \beta_{i_{3}}, u^{0}\right)=F_{23}\left(q, f_{23}(q)\right) \\
& C P_{i_{1}}\left(q, f_{12}(q) \mid \beta_{i_{1}}, u^{0}\right)=C P_{i_{3}}\left(q, f_{13}(q) \mid \beta_{i_{3}}, u^{0}\right)=F_{13}\left(q, f_{13}(q)\right)
\end{aligned}
$$

The single-crossing condition and the monotony of the boundary between two groups involve the either the curves $f_{12}(q), f_{23}(q), f_{13}(q)$ are similar, or each pair of curves has only one intersection point.

By definition of the "outside the market" alternative and of the participative constraint:

$$
f_{12}(0)=f_{23}(0)=f_{13}(0)=0
$$


Consequently, if the curves do not coincide they cross each other in the same point $(0,0)$.

Let $f_{12}(q) \neq f_{23}(q) \neq f_{13}(q)$, if $q \neq 0$. We first suppose that:

$$
f_{12}(\tilde{q})<f_{23}(\tilde{q})<f_{13}(\tilde{q}), \forall \tilde{q}>0 .
$$

We adopt the following notation for a given level of $q(q=\tilde{q})$ :

$$
\begin{aligned}
& \tilde{s}_{12}=f_{12}(\tilde{q}) ; \\
& \tilde{s}_{23}=f_{23}(\tilde{q}) ; \\
& \tilde{s}_{13}=f_{13}(\tilde{q}) .
\end{aligned}
$$

$1^{\circ}$. By replacing the point $\left(\tilde{q}, \tilde{s}_{12}\right)$ into (B.13), we obtain:

$$
C P_{i_{1}}\left(\tilde{q}, \tilde{s}_{12} \mid \beta_{i_{1}}, u^{0}\right)=C P_{i_{2}}\left(\tilde{q}, \tilde{s}_{12} \mid \beta_{i_{2}}, u^{0}\right)=F_{12}\left(\tilde{q}, \tilde{s}_{12}\right) \doteq \tilde{F}_{12}
$$

We use also the notation $\tilde{h}_{12}$ for the level of $H$ corresponding to iso$\mathrm{H}$ curves of groups $i_{1}$ and $i_{2}$, which cross each other in the point $\left(\tilde{q}, \tilde{s}_{12}\right)$. Follow (B.17), the price corresponding to the iso-H curve $\tilde{h}_{12}$ is $\tilde{F}_{12}$. Given the proof of the proposition 3 (see Appendix B.1), the iso-H curve of the group $i_{1}$ is located to the left of the iso-H curve of the groups $i_{2}$.

Let $\left(q_{223}^{\prime}, s_{223}^{\prime}\right)$ the intersection point of the iso-H curve of the group $i_{2}$ $\left(h_{i_{2}}\left(q, s \mid \beta_{i_{2}}\right)=\tilde{h}_{12}\right)$ and of the intersection curve of groups $i_{2}$ and $i_{3}$ participative constraints $\left(s=f_{23}(q)\right)$.

$$
E_{i_{2}}\left(q_{223}^{\prime}, s_{223}^{\prime}\right)=\tilde{F}_{12}
$$

because of the iso-H curve of the group $i_{2}$ corresponding to iso-price $\tilde{F}_{12}$.

We study now the iso-H curve of the group $i_{3}$, passing through the point $\left(q_{223}^{\prime}, s_{223}^{\prime}\right)$. As this point belongs to the intersection curve of the groups $i_{2}$ and $i_{3}$ participative constraints, it follows that:

$$
E_{i_{3}}\left(q_{223}^{\prime}, s_{223}^{\prime}\right)=E_{i_{3}}\left(q_{223}^{\prime}, s_{223}^{\prime}\right)=\tilde{F}_{12}
$$

As $f_{23}(q)>f_{12}(q), \forall q>0$, the iso-H curve of the group $i_{2}$ is located on the right of the curve $f_{23}(q)$, what is contrary to the proof of the proposition 3. Thus we obtain that

$$
f_{23}(q)<f_{12}(q), \forall q>0 .
$$

$2^{\circ}$. We study now the point $\left(\tilde{q}, \tilde{s}_{23}\right)$.

By replacing it to the (B.14), we obtain:

$$
C P_{i_{2}}\left(\tilde{q}, \tilde{s}_{23} \mid \beta_{i_{2}}, u^{0}\right)=C P_{i_{3}}\left(\tilde{q}, \tilde{s}_{23} \mid \beta_{i_{3}}, u^{0}\right)=F_{23}\left(\tilde{q}, \tilde{s}_{23}\right) \doteq \tilde{F}_{23}
$$


Let $\left(q_{212}^{\prime}, s_{212}^{\prime}\right)$ the intersection point of the iso-H curve of the group $i_{2}$ corresponding to the price level $\tilde{F}_{23}$, and of the intersection curve of the groups $i_{1}$ and $i_{2}$ participative constraints, $\tilde{f}_{12}$. Thus,

$$
C P_{i_{2}}\left(q_{212}^{\prime}, s_{212}^{\prime}\right)=\tilde{F}_{23}
$$

Let $\left(q_{312}^{\prime}, s_{312}^{\prime}\right)$ the intersection point of the iso-H curve of the group $i_{3}$ corresponding to the price level $\tilde{F}_{23}$, and of the intersection curve of the groups $i_{1}$ and $i_{2}$ participative constraints, $\tilde{f}_{12}$. So, we obtain for the iso-H curve of the group $i_{2}$ passing through the point $\left(q_{312}^{\prime}, s_{312}^{\prime}\right)$

$$
C P_{i_{2}}\left(q_{312}^{\prime}, s_{312}^{\prime}\right)=C P_{i_{3}}\left(q_{312}^{\prime}, s_{312}^{\prime}\right)=\tilde{F}_{23}
$$

The conditions (B.21) and (B.22) mean that

$$
C P_{i_{2}}\left(q_{212}^{\prime}, s_{212}^{\prime}\right)=C P_{i_{2}}\left(q_{312}^{\prime}, s_{312}^{\prime}\right)
$$

or equivalently

$$
f_{12}\left(q_{212}^{\prime}\right)=f_{12} q_{312}^{\prime}
$$

what is contrary to the strict monotony of the function $s=f_{12}(q)$.

Finally we obtain that intersection curve $f_{12}(q)$ coincide with the intersection curve $f_{23}(q), \forall q>0$.

By proceeding in the same way we obtain $f_{12}(q)=f_{13}(q)$, and thus all participative constraints have the same intersection curve. Q.E.D.

\section{B.5 Demonstration of the proposition 6}

Let study the $1^{\text {st }}$ group. According to the relationship between group's weight, $\eta_{1}$, and the market share available for this group to the left of the curve $F(q, f(q))$, called $\Pi(f(q))$, two cases are possible:

$$
\begin{array}{ll}
\text { Case (a): } & \Pi(f(q)) \leq \eta_{1}, \\
\text { Case (b): } & \Pi(f(q))>\eta_{1},
\end{array}
$$

where the share $\Pi(f(q))$ is defined according to the intersection curve $s=$ $f(q)$ achieves the maximum level of $S$ inside or outside the domain of the variable $Q$ (see graphics of the figure 9):

$$
\Pi(f(q))=\left[\begin{array}{l}
\int_{0}^{S_{\max }} \int_{0}^{f^{-1}(s)} \varphi(q, s) \mathrm{d} q \mathrm{~d} s, \text { si } S_{\max } \leq Q_{\max } \\
\int_{0}^{f\left(Q_{\max }\right)} \int_{0}^{f^{-1}(s)} \varphi(q, s) \mathrm{d} q \mathrm{~d} s+ \\
+\int_{f\left(Q_{\max }\right)}^{S_{\max }} \int_{0}^{Q_{\max }} \varphi(q, s) \mathrm{d} q \mathrm{~d} s, \text { si } S_{\max }>Q_{\max }
\end{array}\right.
$$


Figure 9: Two cases for market share $\Pi(f(q))$ calculus

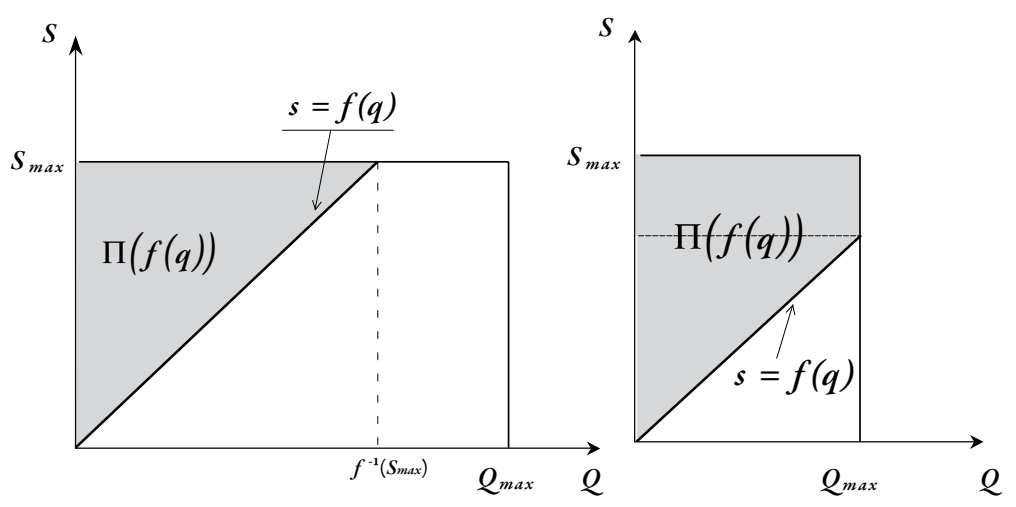

Case (a). The market share $\Pi(f(q))$ is lower that the $1^{\text {st }}$ group's weight

The condition (B.23) involves that consumers of the $1^{\text {st }}$ group are located at equilibrium on their participative constraint $C P_{1}$. According to (B.23) and (17) the boundary between the group 1 and the group 2 is located to the right of the curve of intersection of participatory constraints, i.e. where groups' participative constraints are ordered in increasing order of the parameter $\beta$. In this case, if at equilibrium the individuals of the $1^{\text {st }}$ group are on their participative constraint, consumers in other groups can not even consider the purchase of goods purchased by the consumers of the $1^{\text {st }}$ group on the left of the intersection because their participative constraints are below that the one of the $1^{\text {st }}$ group. The boundary between groups 1 and 2 of plan $(Q, S)$ is defined using the following equation: ${ }^{14}$

$$
\int_{0}^{S_{\max }^{1}} \int_{0}^{g_{12}^{-1}(s)} \varphi(q, s) \mathrm{d} q \mathrm{~d} s=\eta_{1} .
$$

Proceeding in the same way as in the case of assumption $\left(H^{\prime} 1\right)$ and $\left(H^{\prime} 2\right)$, (where the intersection of participative constraints belongs to the plane of coordinates $(S, P)$ )we obtain that at equilibrium, consumers of groups $2,3, \ldots, N$ are located on the incentive constraints of their group with respect to the previous group and the boundary $s=g_{i-1, i}(q)$ between two groups $i$ and $i-1$ is defined implicitly from the equation:

$$
\sum_{k=1}^{i-1} \Pi_{k}\left(g_{k, k+1}(q)\right)=\sum_{k=1}^{i-1} \eta_{k}, i \geq 2 ;
$$

\footnotetext{
${ }^{14}$ If the condition (B.23) is an equality, it means that at equilibrium the group 2 participative constraint is also saturated, and starting from the group 3 the incentive constraints with the previous group are saturated.
} 
where the sum of the market shares $\sum_{k=1}^{i-1} \Pi_{k}\left(g_{k, k+1}(q)\right)$ is defined according to the disposition of the boundary between two groups $s=g_{i-1, i}(q)$ with respect to variables $Q$ and $S$ domains (see the graphs of the figure 10):

$$
\sum_{k=1}^{i-1} \Pi_{k}\left(g_{k, k+1}(q)\right)=\left[\begin{array}{l}
\int_{S_{\min }^{i-1}}^{S_{\max }} \int_{Q_{\min }^{i-1, i}}^{g_{-1}^{-1}(s)} \varphi(q, s) \mathrm{d} q \mathrm{~d} s, \text { si } S_{\max } \leq Q_{\max }, \\
\int_{S_{\min }^{i-1}}^{g_{i-1}\left(Q_{\max }\right)} \int_{Q_{\min }^{i-1}}^{g_{i-1}^{-1}(s)} \varphi(q, s) \mathrm{d} q \mathrm{~d} s \\
+\int_{g_{i-1, i}\left(Q_{\max }\right)}^{S_{\max }} \int_{0}^{Q_{\max }} \varphi(q, s) \mathrm{d} q \mathrm{~d} s, \text { si } S_{\max }>Q_{\max } ;
\end{array}\right.
$$

où $\left\{\begin{array}{l}S_{\min }^{i-1}=g_{i-1, i}(0), \\ Q_{\min }^{i-1}=0,\end{array} \quad\right.$ si $g_{i-1, i}(0) \geq 0$, et $\left\{\begin{array}{l}S_{\min }^{i-1}=0, \\ Q_{\min }^{i-1}=g_{i-1, i}^{-1}(0),\end{array} \quad\right.$ si $g_{i-1, i}^{-1}(0) \geq 0$.

Figure 10: Calculus of $\sum_{k=1}^{i-1} \Pi_{k}\left(g_{k, k+1}(q)\right)$
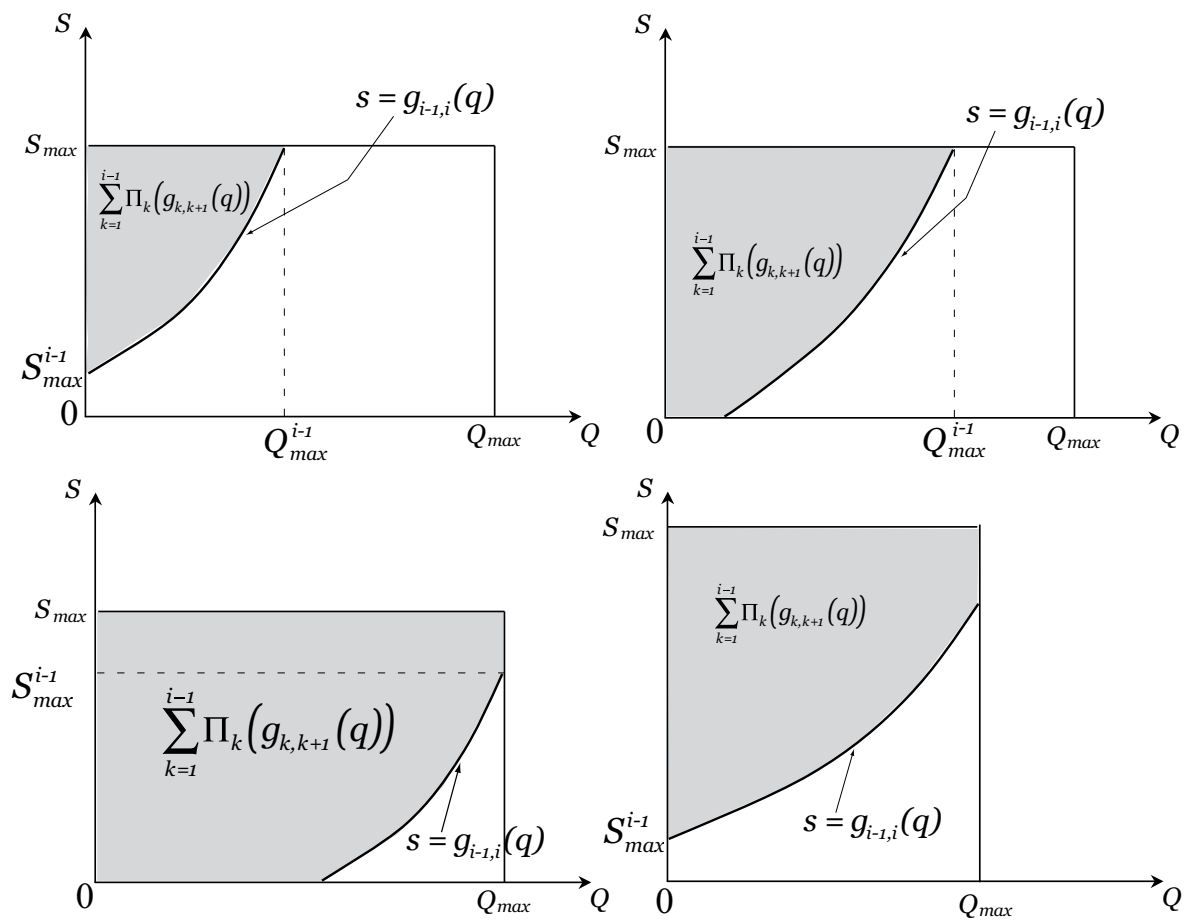


\section{Case (b). The market share $\Pi(f(q))$ is higher than the $1^{\text {st }}$ group weight}

The condition (B.24) implies that at equilibrium, consumers of the first group can not be situated on their constraint participative $C P_{1}$. Indeed, if they could, the boundary between the groups 1 and 2 would be located to the left of the intersection curve $F(q, f(q))$, where groups' participative constraints are ordered by inverse order of preference parameters $\beta$. Thus the surface $C P_{1}$ would be above the surface $C P_{2}$ on the corresponding points on the frontier between the two groups. The consumers of the group 2 can not be located above the surface $C P_{2}$, so if the situation described above is an equilibrium, then the prices of homes purchased by the group 2 would be located below the equilibrium bid surface of the group 1 , which is contrary to the proposition 2 .

In contrast, consumers of the group 2 may be located on their constraint participative $\mathrm{CP}_{2}$ at equilibrium, subject to the boundary between groups 2 and 3 located to the right of the intersection of participative constraints:

$$
\begin{gathered}
\eta_{1}+\eta_{2} \geq \Pi(f(q)) \\
\Pi(f(q))=\left[\begin{array}{l}
\int_{0}^{S_{\max }} \int_{0}^{f^{-1}(s)} \varphi(q, s) \mathrm{d} q \mathrm{~d} s, \quad \text { if } S_{\max } \leq Q_{\max } ; \\
\int_{0}^{f\left(Q_{\max }\right)} \int_{0}^{f^{-1}(s)} \varphi(q, s) \mathrm{d} q \mathrm{~d} s+\int_{f\left(Q_{\max }\right)}^{S_{\max }} \int_{0}^{Q_{\max }} \varphi(q, s) \mathrm{d} q \mathrm{~d} s, \quad \text { if } S_{\max }>Q_{\max }
\end{array}\right.
\end{gathered}
$$

In this case, the consumers of the group 1 are located at equilibrium on the bid surface which is the incentive constraint of the group 1 with respect to group 2, passing through the boundary between the groups 1 and 2 . The function of hedonic price equilibrium for the groups $3,4, \ldots, I$, is defined as in the case (a): on the basis of incentive constraints of the group relative to the previous group, passing through boundary between the groups.

Let $s=g_{12}(q)$ the equilibrium boundary between the groups 1 and 2 (projection on the plan $(Q, S)), s=g_{23}(q)$ the equilibrium boundary between the groups 2 and $3, \ldots, s=g(i, i+1)$ the equilibrium boundary between the groups $i$ and $i+1$. So the equilibrium hedonic price function is composed on segments $E_{1}^{*}, E_{2}^{*}, E_{3}^{*}, \ldots, E_{N}^{*}$, such that the following equations are satisfied:

$$
\begin{aligned}
& E_{2}^{*}=C P_{2}\left(q, s \mid \beta_{2}, u_{2}^{*}\right), \\
& V\left(h\left(q, s \mid \beta_{1}\right), E_{1}^{*}\left(q, s \mid \beta_{1}, u_{1}^{*}\right)\right)=V\left(h\left(q, g_{12}(q) \mid \beta_{1}\right), E_{2}^{*}\left(q, g_{12}(q) \mid \beta_{2}, u_{2}^{*}\right)\right) \\
& V\left(h\left(q, s \mid \beta_{i}\right), E_{i}^{*}\left(q, s(q) \mid \beta_{i}, u_{i}^{*}\right)\right) \\
= & V\left(h\left(q, g_{i-1, i}(q) \mid \beta_{i}\right), E_{i-1}^{*}\left(q, g_{i-1, i}(q) \mid \beta_{i-1}, u_{i-1}^{*}\right)\right), i \in\{3, \ldots, I\}
\end{aligned}
$$




$$
\begin{aligned}
& \forall i \in\{1, \ldots, I-1\}: \\
& s=g_{i, i+1}(q): E_{i}^{*}\left(q, g_{i, i+1} \mid \beta_{i}, u_{i}^{*}\right)=E_{i+1}^{*}\left(q, g_{i, i+1} \mid \beta_{i+1}, u^{i+1}\right) \\
& \sum_{k=1}^{i} \Pi_{i}\left(g_{i, i+1}(q)\right)=\sum_{k=1}^{i} \eta_{i}, i \in\{1, \ldots, I\} \\
& \sum_{k=1}^{i} \Pi_{i}\left(g_{i, i+1}(q)\right)=\left[\begin{array}{l}
\int_{S_{\min }^{i}}^{S_{\max }} \int_{Q_{\min }^{i}}^{g_{i, i+1}^{-1}(s)} \varphi(q, s) \mathrm{d} q \mathrm{~d} s, \text { si } S_{\max } \leq Q_{\max } \\
\int_{S_{\min }^{i}}^{g_{i, i+1}\left(Q_{\max }\right)} \int_{Q_{\min }^{i}}^{g_{i, i+1}^{-1}(s)} \varphi(q, s) \mathrm{d} q \mathrm{~d} s \\
+\int_{g_{i, i+1}\left(Q_{\max }\right)}^{S_{\max }} \int_{0}^{Q_{\max }} \varphi(q, s) \mathrm{d} q \mathrm{~d} s, \text { si } S_{\max }>Q_{\max }
\end{array}\right.
\end{aligned}
$$

The segments limits are defined according to the disposition of boundaries on the left and on the right of each segment (see Figure 3 which illustrates different possible configurations). Thus, on each interior segment, $\forall 1<i<I, q \in\left[Q_{\min }^{i}, Q_{\max }^{i}\right], s \in\left[S_{\min }^{i}, S_{\max }^{i}\right]$ :

$Q_{\min }^{i}=\left[\begin{array}{ll}0, \quad \text { if } g_{i-1, i}(0) \geq 0, \\ g_{i-1, i}^{-1}(0), \quad \text { if } g_{i-1, i}^{-1}(0) \geq 0 ;\end{array} \quad Q_{\max }^{i}=\left[\begin{array}{ll}g_{i, i+1}^{-1}\left(S_{\max }\right), & \text { if } g_{i, i+1}\left(Q_{\max }\right) \geq S_{\max }, \\ Q_{\max }, & \text { if } g_{i, i+1}\left(Q_{\max }\right)<S_{\max }\end{array}\right.\right.$

$S_{\min }^{i}=\left[\begin{array}{ll}g_{i, i+1}(0), \text { if } g_{i, i+1}(0) \geq 0, \\ 0, \quad \text { si } g_{i, i+1}^{-1}(0) \geq 0 ;\end{array} S_{\max }^{i}=\left[\begin{array}{ll}S_{\max }, & \text { if } g_{i-1, i}\left(Q_{\max }\right) \geq S_{\max } \\ g_{i-1, i}\left(Q_{\max }\right), & \text { if } g_{i-1, i}\left(Q_{\max }\right)<S_{\max }\end{array}\right.\right.$

For the first segment, $i=1, q \in\left[0, Q_{\max }^{1}\right], s \in\left[S_{\min }^{1}, S_{\max }\right]$ :

$Q_{\max }^{1}=\left[\begin{array}{ll}g_{1,2}^{-1}\left(S_{\max }\right), & \text { if } g_{1,2}\left(Q_{\max }\right) \geq S_{\max }, \\ Q_{\max }, & \text { if } g_{1,2}\left(Q_{\max }\right)<S_{\max } .\end{array} \quad S_{\min }^{1}=\left[\begin{array}{l}g_{1,2}(0), \quad \text { if } g_{1,2}(0) \geq 0 \\ 0, \quad \text { if } g_{1,2}^{-1}(0) \geq 0\end{array}\right.\right.$

For the last segment, $i=I, q \in\left[Q_{\min }^{N}, Q_{\max }\right], s \in\left[0, S_{\max }^{N}\right]$ :

$Q_{\min }^{N}=\left[\begin{array}{ll}g_{N-1, N}^{-1}(0), & \text { if } g_{N-1, N}^{0}(0) \geq 0, \\ 0, & \text { if } g_{N-1, N}(0) \geq 0 .\end{array} \quad S_{\max }^{N}=\left[\begin{array}{l}S_{\max }, \quad \text { if } g_{N-1, N}\left(Q_{\max }\right) \geq S_{\max }, \\ g_{N-1, N}\left(Q_{\max }\right), \quad \text { if } g_{N-1, N}\left(Q_{\max }\right)<S_{\max }\end{array}\right.\right.$

Recall the condition (B.30) necessary for the equilibrium described above:

$$
\begin{gathered}
\eta_{1}+\eta_{2} \geq \Pi(f(q)), \\
\text { where } \Pi(f(q))=\left[\begin{array}{l}
\int_{0}^{S_{\max }} \int_{0}^{f^{-1}(s)} \varphi(q, s) \mathrm{d} q \mathrm{~d} s, \quad \text { if } S_{\max } \leq Q_{\max } \\
\int_{0}^{f\left(Q_{\max }\right)} \int_{0}^{f^{-1}(s)} \varphi(q, s) \mathrm{d} q \mathrm{~d} s+ \\
\int_{f\left(Q_{\max }\right)}^{S_{\max }} \int_{0}^{Q_{\max }} \varphi(q, s) \mathrm{d} q \mathrm{~d} s, \text { if } S_{\max }>Q_{\max }
\end{array}\right.
\end{gathered}
$$


This condition can be generalized for all groups and finally we obtain: the group $i^{\circ}$ which saturates its participative constraint at equilibrium can be find from the following condition:

$$
i^{\circ}=\min _{i \in\{1, \ldots, I\}} i: \sum_{k=1}^{i} \eta_{k} \geq \Pi(f(q)) .
$$

Q.E.D.

\section{B.6 Demonstration of the theorem 5}

We proceed in the same was as for the demonstration of the theorem 4 from the Appendix B.3.

We first study the part of the hedonic price surface corresponding to a group $i$ equilibrium bid funciton. By the definition 2 of the individual bid function, the equilibrium prices for the group $i$ satisfy:

$$
V\left(h(q, s), P^{*}(q, s)\right)=u_{i}^{*}, \quad(q, s) \in D h_{i}
$$

where $u_{i}^{*}$ is equilibrium reference utility of the group $i$, and $D h_{i}$ is its definition domain equal to $\left[Q_{i}^{\min }, Q_{i}^{\max }\right] \times\left[S_{i}^{\min }, S_{i}^{\max }\right]$.

The partial derivative of $(\mathrm{B} .43)$ with respect to $Q$, and with respect to $S$, give:

$$
\begin{aligned}
& \left.\frac{\partial P}{\partial Q}\right|_{(q, s) \in D h_{i}}=-\left.\frac{\partial V / \partial h \partial h / \partial Q}{\partial V / \partial P}\right|_{(q, s) \in D h_{i}}, \\
& \left.\frac{\partial P}{\partial S}\right|_{(q, s) \in D h_{i}}=-\left.\frac{\partial V / \partial h \partial h / \partial S}{\partial V / \partial P}\right|_{(q, s) \in D h_{i}} .
\end{aligned}
$$

The equations (B.44) and (B.45) are verified for each group $i \in\{1, \ldots, I\}$.

We now study two adjacent groups $i$ and $i+1$. The Spence-Mirrlees conditions $H^{\prime \prime} 1$ and $H^{\prime \prime} 2$, involve that:

$$
\begin{gathered}
\frac{\partial}{\partial \beta}\left(\frac{\partial P}{\partial Q}\right)>0, \forall S, \forall \beta, \\
\frac{\partial}{\partial \beta}\left(\frac{\partial P}{\partial S}\right)<0, \forall Q, \forall \beta .
\end{gathered}
$$

Consequently:

$$
\begin{aligned}
& \left.\frac{\partial P_{i}^{*}}{\partial Q}\right|_{q=Q_{i}^{\max }, s=g_{i, i+1}(q)}<\left.\frac{\partial P_{i+1}^{*}}{\partial Q}\right|_{q=Q_{i}^{\max }, s=g_{i, i+1}(q)}, \\
& \left.\frac{\partial P_{i}^{*}}{\partial S}\right|_{q=Q_{i}^{\max }, s=g_{i, i+1}(q)}>\left.\frac{\partial P_{i+1}^{*}}{\partial S}\right|_{q=Q_{i}^{\max }, s=g_{i, i+1}(q)},
\end{aligned}
$$

car $\beta_{i}<\beta_{i+1}$.

The inequalities $(\mathrm{B} .48)$ and $(\mathrm{B} .49)$ involve the discontinuity of implicit prices of housing environmental quality and of housing intrinsic quality on the boundaries of the segments. Q.E.D. 


\section{Application to a nested CES direct utility function}

In the case of a nested CES direct utility function the equation of the saturation of the group $i$ participative constraint, $C P_{i}$, becomes:

$$
\begin{aligned}
& {\left[\alpha\left(\beta_{i} q^{\sigma}+\left(1-\beta_{i}\right) s^{\sigma}\right)+(1-\alpha)\left(R-C P_{i}(q, s)\right)^{\sigma}\right]^{\frac{1}{\sigma}}=(1-\alpha)^{\frac{1}{\sigma}} R} \\
& C P_{i}(q, s)=R-\left[R^{\sigma}-\frac{\alpha}{1-\alpha}\left(\beta_{i} q^{\sigma}+\left(1-\beta_{i}\right) s^{\sigma}\right)\right]^{\frac{1}{\sigma}}
\end{aligned}
$$

The solution of the equation $C P_{i}(q, s)=C P_{j}(q, s)$ provides the equation of the intersection curve of participative constraints $C P_{i}(q, s)$ and $C P_{j}(q, s)$ :

$$
s=q .
$$

According to the theoretical result, the intersection function is increasing in $q$ and does not depend on the $\beta$.

The group $i$ equilibrium bid function for the nested CES specification case is written:

$$
E_{i}^{*}\left(q, s \mid \beta_{i}, u_{i}^{*}\right)=R-\left[\frac{1}{1-\alpha}\left(u_{i}^{*}\right)^{\sigma}-\frac{\alpha}{1-\alpha}\left(\beta_{i} q^{\sigma}+\left(1-\beta_{i}\right) s^{\sigma}\right)\right]^{\frac{1}{\sigma}},
$$

where $u_{i}^{*}$ is the reference utility level in the bid function definition.

According to the proposition [6] the group for which the participative constraint is saturated, is obtained from:

$$
\sum_{k=1}^{i^{\circ}} \eta_{k} \geq \Pi(f(q))
$$

where

$$
\Pi(f(q))=\left[\begin{array}{l}
\int_{0}^{S_{\max }} \int_{0}^{f^{-1}(s)} \varphi(q, s) \mathrm{d} q \mathrm{~d} s, \text { if } S_{\max } \leq Q_{\max } \\
\int_{0}^{f\left(Q_{\max }\right)} \int_{0}^{f^{-1}(s)} \varphi(q, s) \mathrm{d} q \mathrm{~d} s \\
+\int_{f\left(Q_{\max }\right)}^{S_{\max }} \int_{0}^{Q_{\max }} \varphi(q, s) \mathrm{d} q \mathrm{~d} s, \text { if } S_{\max }>Q_{\max } .
\end{array}\right.
$$

In the case of an uniform joint density function and by replacing $f^{-1}(s)$ by the equation (C.3), the condition is written:

$$
\sum_{k=1}^{i^{\circ}} \eta_{k} \geq\left[\begin{array}{l}
\frac{S_{\max }}{2 Q_{\max }}, \quad \text { if } S_{\max } \leq Q_{\max } \\
1-\frac{Q_{\max }}{2 S_{\max }}, \quad \text { if } S_{\max }>Q_{\max }
\end{array}\right.
$$


One defined the group $i^{\circ}$ which saturates its participative constraint, the hedonic price function corresponds on the interval $\left[Q_{\min }^{i^{\circ}}, Q_{\max }^{i^{\circ}}\right] \times\left[S_{\min }^{i^{\circ}}, S_{\max }^{i^{\circ}}\right]$ to the participative constraint of this group:

$$
\begin{gathered}
P_{i^{\circ}}^{*}=E_{i^{\circ}}^{*}=C P_{i^{\circ}}=R-\left[R^{\sigma}-\frac{\alpha}{1-\alpha}\left(\beta_{i^{\circ}} q^{\sigma}+\left(1-\beta_{i^{\circ}}\right) s^{\sigma}\right)\right]^{\frac{1}{\sigma}}, \\
q \in\left[Q_{\min }^{i^{\circ}}, Q_{\max }^{i^{\circ}}\right], s \in\left[S_{\min }^{i^{\circ}}, S_{\max }^{i^{\circ}}\right],
\end{gathered}
$$

where the segment limits are defined from the equations (B.38)-(B.41).

At equilibrium according to the theorem 3 for the consumers of groups $i$, such that $i<i^{\circ}$, the hedonic price function corresponds to their incentive constraints with respect to the next group, passing through the boundary with the next group. The equation of the boundary, $s=g_{i, i+1}(q)$ is obtained from the equation (41):

$$
\begin{aligned}
& \left(u_{i}^{*}\right)^{\sigma}-\alpha\left(\beta_{i} q^{\sigma}+\left(1-\beta_{i}\right) s^{\sigma}\right)=\left(u_{i+1}^{*}\right)^{\sigma}-\alpha\left(\beta_{i+1} q^{\sigma}+\left(1-\beta_{i+1}\right) s^{\sigma}\right) ; \\
& s=\left(q^{\sigma}-\frac{\left(u_{i+1}^{*}\right)^{\sigma}-\left(u_{i}^{*}\right)^{\sigma}}{\alpha\left(\beta_{i+1}-\beta_{i}\right)}\right)^{\frac{1}{\sigma}}
\end{aligned}
$$

and the incentive constraint of the group $i$ with respect to the group $i+1$ (equation (39) of the theorem 3) becomes in this case:

$$
\begin{aligned}
& {\left[\alpha\left(\beta_{i} q^{\sigma}+\left(1-\beta_{i}\right) s^{\sigma}\right)+(1-\alpha)\left(R-E_{i}\left(q, s \mid \beta_{i}, u_{i}^{*}\right)\right)^{\sigma}\right]^{\frac{1}{\sigma}} } \\
= & {\left[\alpha\left(\beta_{i} \tilde{q}^{\sigma}+\left(1-\beta_{i}\right) \tilde{s}^{\sigma}\right)+(1-\alpha)\left(R-E_{i+1}\left(\tilde{q}, \tilde{s} \mid \beta_{i+1}, u_{i+1}^{*}\right)\right)^{\sigma}\right]^{\frac{1}{\sigma}}, } \\
& \tilde{s}=g_{i, i+1}(\tilde{q})=\left(\tilde{q}^{\sigma}-\frac{\left(u_{i+1}^{*}\right)^{\sigma}-\left(u_{i}^{*}\right)^{\sigma}}{\alpha\left(\beta_{i+1}-\beta_{i}\right)}\right)^{\frac{1}{\sigma}}
\end{aligned}
$$

from which

$$
\begin{aligned}
& E_{i}(q, s)=R-\left[\left(R-E_{i+1}\left(\tilde{q}, \tilde{s} \mid \beta_{i+1}, u_{i+1}^{*}\right)\right)^{\sigma}\right. \\
& \left.-\frac{\alpha}{1-\alpha}\left(\beta q^{\sigma}+\left(1-\beta_{i}\right) s^{\sigma}+\tilde{q}^{\sigma}+\left(1-\beta_{i}\right) \frac{\left(u_{i}^{*}\right)^{\sigma}-\left(u_{i+1}^{*}\right)^{\sigma}}{\alpha\left(\beta_{i+1}-\beta_{i}\right)}\right)\right]^{\frac{1}{\sigma}} .
\end{aligned}
$$

For the consumers of groups $i>i^{\circ}$ the equilibrium housing price corresponds to their incentive constraints with respect to the previous group. The equation of the boundary is written in this case:

$$
s=\left(q^{\sigma}-\frac{\left(u_{i}^{*}\right)^{\sigma}-\left(u_{i-1}^{*}\right)^{\sigma}}{\alpha\left(\beta_{i}-\beta_{i-1}\right)}\right)^{\frac{1}{\sigma}}
$$


and the incentive constraint (equation 40 of the theorem 3) becomes:

$$
\begin{aligned}
& {\left[\alpha\left(\beta_{i} q^{\sigma}+\left(1-\beta_{i}\right) s^{\sigma}\right)+(1-\alpha)\left(R-E_{i}\left(q, s \mid \beta_{i}, u_{i}^{*}\right)\right)^{\sigma}\right]^{\frac{1}{\sigma}}} \\
& =\left[\alpha\left(\beta_{i} \tilde{q}^{\sigma}+\left(1-\beta_{i}\right) \tilde{s}^{\sigma}\right)+(1-\alpha)\left(R-E_{i-1}\left(\tilde{q}, \tilde{s} \mid \beta_{i-1}, u_{i-1}^{*}\right)\right)^{\sigma}\right]^{\frac{1}{\sigma}}, \\
& \tilde{s}=g_{i, i-1}(\tilde{q})=\left(\tilde{q}^{\sigma}-\frac{\left(u_{i}^{*}\right)^{\sigma}-\left(u_{i-1}^{*}\right)^{\sigma}}{\alpha\left(\beta_{i}-\beta_{i-1}\right)}\right)^{\frac{1}{\sigma}}
\end{aligned}
$$

for which

$$
\begin{aligned}
& E_{i}(q, s)=R-\left[\left(R-E_{i-1}\left(\tilde{q}, \tilde{s} \mid \beta_{i-1}, u_{i-1}^{*}\right)\right)^{\sigma}\right. \\
& \left.-\frac{\alpha}{1-\alpha}\left(\beta_{i} q^{\sigma}+\left(1-\beta_{i}\right) s^{\sigma}+\tilde{q}^{\sigma}-\left(1-\beta_{i}\right) \frac{\left(u_{i}^{*}\right)^{\sigma}-\left(u^{*} i-1\right)^{\sigma}}{\alpha\left(\beta_{i}-\beta_{i-1}\right)}\right)\right]^{\frac{1}{\sigma}} .
\end{aligned}
$$

The reference utility levels $\left\{u_{i}^{*}\right\}_{i=1}^{N}$ are obtained from the conditions (42)(43) of the equality of market share of a group and its weight (cf. 431). In the case of the nested CES utility function and joint uniform density these conditions are written as:

$$
\begin{aligned}
& \sum_{k=1}^{i} \eta_{k}=\left[\begin{array}{ll}
\int_{S_{\min }^{i}}^{S_{\max }} \int_{Q_{\min }^{i}}^{g_{i, i+1}^{-1}(s)} \varphi(q, s) \mathrm{d} q \mathrm{~d} s, & \text { if } S_{\max } \leq Q_{\max } \\
\int_{S_{\min }^{i}}^{g_{i, i+1}\left(Q_{\max }\right)} \int_{Q_{\min }^{i}}^{g_{i, i+1}^{-1}(s)} \varphi(q, s) \mathrm{d} q \mathrm{~d} s & \\
+\int_{g_{i, i+1}\left(Q_{\max }\right)}^{S_{\max }} \int_{0}^{Q_{\max }} \varphi(q, s) \mathrm{d} q \mathrm{~d} s, & \text { if } S_{\max }>Q_{\max },
\end{array}\right. \\
& i \in\{1, \ldots, I\}
\end{aligned}
$$

$$
\begin{aligned}
& s=g_{i, i+1}(q)=\left(q^{\sigma}-\frac{\left(u_{i+1}^{*}\right)^{\sigma}-\left(u_{i}^{*}\right)^{\sigma}}{\alpha\left(\beta_{i+1}-\beta_{i}\right)}\right)^{\frac{1}{\sigma}} \\
& \varphi(q, s)=\frac{1}{S_{\max } Q_{\max }} \\
& Q_{\min }^{i}=\left[\begin{array}{l}
0, \text { si } g_{i, i+1}(0) \geq 0, \\
g_{i, i+1}^{-1}(0), \text { if } g_{i, i+1}^{-1}(0) \geq 0
\end{array}\right. \\
& S_{\min }^{i}=\left[\begin{array}{l}
g_{i, i+1}(0), \quad \text { if } g_{i, i+1}(0) \geq 0 \\
0, \text { si } g_{i, i+1}^{-1}(0) \geq 0
\end{array}\right.
\end{aligned}
$$

By construction of the equilibrium, $u_{i}^{*}<u_{i+1}^{*}$, if $i^{\circ}<i \leq I-1$, and $u_{i}^{*}>u_{i+1}^{*}$, if $1 \leq i<i^{\circ}$. Consequently: 
A. For the groups $i^{\circ}<i \leq I-1$ (on the right of the group saturates its participative constraint), $g_{i, i+1}^{-1}(0)=\left(\frac{\left(u_{i+1}^{*}\right)^{\sigma}-\left(u_{i}^{*}\right)^{\sigma}}{\alpha\left(\beta_{i+1}-\beta_{i}\right)}\right)^{\frac{1}{\sigma}}>0$, so the expression (C.16) becomes :

A.1. If $S_{\max } \leq Q_{\max }$

$\sum_{k=1}^{i} \eta_{k}=\frac{1}{S_{\max } Q_{\max }} \int_{0}^{S_{\max }}\left(s^{\sigma}+\frac{\left(u_{i+1}^{*}\right)^{\sigma}-\left(u_{i}^{*}\right)^{\sigma}}{\alpha\left(\beta_{i+1}-\beta_{i}\right)}\right)^{\frac{1}{\sigma}} \mathrm{d} s-\frac{1}{Q_{\max }}\left(\frac{\left(u_{i+1}^{*}\right)^{\sigma}-\left(u_{i}^{*}\right)^{\sigma}}{\alpha\left(\beta_{i+1}-\beta_{i}\right)}\right)^{\frac{1}{\sigma}}$

A.2. If $S_{\max }>Q_{\max }$

$$
\begin{aligned}
\sum_{k=1}^{i} \eta_{k} & =\frac{1}{S_{\max } Q_{\max }} \int_{0}^{g_{j, j+1}\left(Q_{\max }\right)}\left(s^{\sigma}+\frac{\left(u_{i+1}^{*}\right)^{\sigma}-\left(u_{i}^{*}\right)^{\sigma}}{\alpha\left(\beta_{i+1}-\beta_{i}\right)}\right)^{\frac{1}{\sigma}} \mathrm{d} s+1 \\
& -\frac{1}{Q_{\max }}\left(\frac{\left(u_{i+1}^{*}\right)^{\sigma}-\left(u_{i}^{*}\right)^{\sigma}}{\alpha\left(\beta_{i+1}-\beta_{i}\right)}\right)^{\frac{1}{\sigma}}-\frac{1}{S_{\max }}\left(Q_{\max }^{\sigma}-\frac{\left(u_{i+1}^{*}\right)^{\sigma}-\left(u_{i}^{*}\right)^{\sigma}}{\alpha\left(\beta_{i+1}-\beta_{i}\right)}\right)^{\frac{1}{\sigma}}
\end{aligned}
$$

B. For groups $1 \leq i<i^{\circ}$ (on the left from the group saturates its participative constraint), $g_{i, i+1}(0)=\left(\frac{\left(u_{i}^{*}\right)^{\sigma}-\left(u_{i+1}^{*}\right)^{\sigma}}{\alpha\left(\beta_{i+1}-\beta_{i}\right)}\right)^{\frac{1}{\sigma}}>0$, so the expression (C.16) becomes:

B.1. If $S_{\max } \leq Q_{\max }$

$$
\begin{gathered}
\sum_{k=1}^{i} \eta_{k}=\frac{1}{S_{\max } Q_{\max }} \int_{S_{\min }^{i}}^{S_{\max }}\left(s^{\sigma}-\frac{\left(u^{(i)}\right)^{\sigma}-\left(u^{(i+1)}\right)^{\sigma}}{\alpha\left(\beta_{i+1}-\beta_{i}\right)}\right)^{\frac{1}{\sigma}} \mathrm{d} s \\
\text { where } S_{\min }^{i}=\left(\frac{\left(u_{i}^{*}\right)^{\sigma}-\left(u_{i+1}^{*}\right)^{\sigma}}{\alpha\left(\beta_{i+1}-\beta_{i}\right)}\right)^{\frac{1}{\sigma}}
\end{gathered}
$$

B.2. If $S_{\max }>Q_{\max }$

$$
\begin{aligned}
\sum_{k=1}^{i} \eta_{k} & =\frac{1}{S_{\max } Q_{\max }} \int_{S_{\min }^{i}}^{g_{j, j+1}\left(Q_{\max }\right)}\left(s^{\sigma}-\frac{\left(u_{i}^{*}\right)^{\sigma}-\left(u_{i-1}^{*}\right)^{\sigma}}{\alpha\left(\beta_{i+1}-\beta_{i}\right)}\right)^{\frac{1}{\sigma}} \mathrm{d} s+ \\
& +1-\frac{1}{S_{\max }}\left(Q_{\max }^{\sigma}-\frac{\left(u_{i+1}^{*}\right)^{\sigma}-\left(u_{i}^{*}\right)^{\sigma}}{\alpha\left(\beta_{i+1}-\beta_{i}\right)}\right)^{\frac{1}{\sigma}} \\
& \text { where } S_{\min }^{i}=\left(\frac{\left(u_{i}^{*}\right)^{\sigma}-\left(u_{i+1}^{*}\right)^{\sigma}}{\alpha\left(\beta_{i+1}-\beta_{i}\right)}\right)^{\frac{1}{\sigma}}
\end{aligned}
$$

\section{References}

Baudry, M. and Maslianskaïa-Pautrel, M. (2011a). Revisiting the hedonic price method to assess the implicit price of environmental quality with market segmentation. Working paper, LEMNA Université de Nantes. 
Baudry, M. and Maslianskaïa-Pautrel, M. (2011b). Une remise en cause de la méthode des prix hédoniques en présence d'une segmentation de marché. Revue Economique, 62(3):567 - 578.

Bayer, P., McMillan, R., and Rueben, K. (2005). An equilibrium model of sorting in an urban housing market. Working paper, Yale University.

Boyle, M. A. and Kiel, K. A. (2001). A survey of house price hedonic studies of the impact of environmental externalities. Journal of Real Estate Literature, 9(2):117-144.

Epple, D. and Platt, G. J. (1998). Equilibrium and local redistribution in an urban economy when households differ in both preferences and incomes. Journal of Urban Economics, 43(1):23-51.

Epple, D. and Sieg, H. (1999). Estimating equilibrium models of local jurisdictions. Journal of Political Economy, 107(4):645-681.

Kuminoff, N. (2006). Recovering Preferences for Public Goods from a DualMarket Locational Equilibrium. PhD thesis, North Carolina State University.

Kuminoff, N. V. (2009). Decomposing the structural identification of nonmarket values. Journal of Environmental Economics and Management, $57(2): 123-139$.

Lancaster, K. J. (1966). A new approach to consumer theory. Journal of Political Economy, 74(2):132-157.

Rosen, S. (1974). Hedonic prices and implicit markets: Product differentiation in pure competition. Journal of Political Economy, 82(1):34-55.

Simons, R. A. and Saginor, J. D. (2006). A meta-analysis of the effect of environmental contamination and positive amenities on residential real estate values. Journal of Real Estate Research, 28(1):71-104.

Tiebout, C. M. (1956). A pure theory of local expenditures. The Journal of Political Economy, 64(5):416-424. 
12-1. What drives Health Care Expenditure in France since 1950? A time-series study with structural breaks and non-linearity approaches

Thomas Barnay, Olivier Damette

12-2. How to account for changes in the size of Sports Leagues : The Iso Competitive Balance Curves

Jean-Pascal Gayant, Nicolas Le Pape

\section{TEPP Working Papers 2011}

11-1. The French "Earned Income Supplement" (RSA) and back-to-work incentives Denis Anne, Yannick L'Horty

11-2. The effect of place of residence on access to employment: a field experiment on qualified young job applicants in Ile-de-France

Yannick L'Horty, Emmanuel Duguet, Loïc du Parquet, Pascale Petit, Florent Sari

11-3. Why is there a faster return to work near the border?

Jonathan Bougard

11-4. Residential Discrimination and Ethnic Origin: An experimental assessment in the Paris suburbs

Emmanuel Duguet, Yannick L'Horty, Pascale Petit

11-5.The Fateful Triangle : Complementarities between product, process and organisational innovation in the UK and France

Gérard Ballot, Fathi Fakhfakh, Fabrice Galia, and Ammon Salter

11-6. How important is innovation? A Bayesian factor-augmented productivity model on panel data

Georges Bressona, Jean-Michel Etienne, Pierre Mohnen

11-7. Fiscal Shocks in a Two Sector Open Economy

Olivier Cardi, Romain Restout

11-8. Productivity, Capital and Labor in Labor-Managed and Conventional Firms

Fathi Fakhfakh, Virginie Pérotin, Mónica Gago

11-9. What is the Natural Weight of the Current Old ?

Damien Gaumont, Daniel Leonard

11-10. Routinization-Biased Technical Change, Globalization and Labor Market Polarization: Does Theory Fit the Facts?

Jaewon Jung, Jean Mercenier 
The CNRS Institute for Labor Studies and Public Policies (the TEPP Institute, FR $n^{\circ} 3126$ CNRS) gathers together research centres specializing in economics and sociology:

- the Centre d'Etudes de I'Emploi (Centre for Employment Studies), CEE, Public Administrative Organization, under the leadership of the Ministers of Work and Research

- l'Equipe de Recherche sur les Marchés, l'Emploi et la Simulation (Research Team on Markets, Employment and Simulation), ERMES, University of Paris II PanthéonAssas

- the Centre d'Etudes des Politiques Economiques de l'université d'Evry (Research Centre focused on the analysis of economic policy and its foundations and implications), EPEE, University of Evry Val d'Essonne

- the Centre Pierre Naville (Research on Work and Urban Policies), CPN, University of Evry Val d'Essonne

- l'Equipe de Recherche sur l'Utilisation des Données Temporelles en Economie (Research Team on Use of Time Data in Economics), ERUDITE, University of ParisEst Créteil and University of Paris-Est Marne-la-Vallée

- the Groupe d'Analyse des Itinéraires et des Niveaux Salariaux (The Group on Analysis of Wage Levels and Trajectories), GAINS, University of the Maine

The TEPP Institute brings together 147 researchers and research professors and $100 \mathrm{PhD}$ students who study changes in work and employment in relation to the choices made by firms and analyse public policies using new evaluation methods. 